\title{
Electronic and Dielectric Properties of MoV-Oxide (M1 Phase) under Alkane Oxidation Conditions
}

\author{
Anna M. Wernbacher, ${ }^{\dagger}$ Pierre Kube, ${ }^{\dagger}$ Michael Hävecker, ${ }^{\ddagger}$ Robert Schlögl, ${ }^{\dagger, \dagger}$ and Annette Trunschke ${ }^{* \dagger \dagger}$ \\ ${ }^{\dagger}$ Department of Inorganic Chemistry, Fritz-Haber-Institut der Max-Planck-Gesellschaft, Faradayweg 4-6, 14195 Berlin, Germany \\ ${ }^{\ddagger}$ Department Heterogeneous Reactions, Max Planck Institute for Chemical Energy Conversion, Stiftstrasse 34-36, 45470 Mülheim \\ an der Ruhr, Germany
}

Supporting Information

ABSTRACT: Isostructural orthorhombic oxides of the general formula $(\mathrm{Mo}, \mathrm{V}, \mathrm{Te}, \mathrm{Sb}, \mathrm{Nb}, \mathrm{Ta}) \mathrm{O}_{\mathrm{x}}$ are an important class of solids, which are interesting as catalysts for oxidation of light alkanes. We investigated relations between the electronic properties of $\mathrm{MoV}$-oxide (orthorhombic M1 phase) and its catalytic performance in the oxidation of ethane, propane, and $n$-butane. Operando conductivity and permittivity measurements were performed and complemented by near-ambient-pressure X-ray photoelectron spectroscopy. In contrast to the n-type MoVTeNb-oxide, MoV-oxide showed p-type semiconducting behavior. The conductivity of the sample adapted sensitively to the surrounding atmosphere, not only to alkane chain lengths but also to reactant conversion levels. However, no measurable change in band bending depending on the alkane chain length was observed,

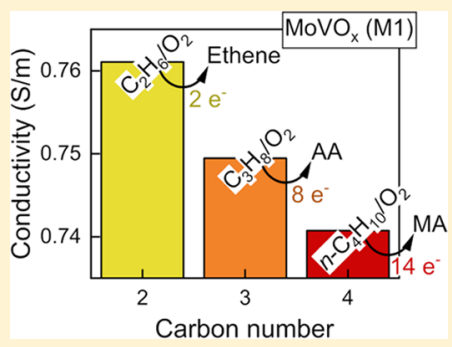
indicating that the gas-phase-dependent surface potential barrier, which controls the charge transfer between reactants and catalyst, is less pronounced or missing in dry alkane oxidation feeds. The addition of steam in propane oxidation led to a decrease of its conductivity and work function. Steam significantly influenced the surface layer on MoV-oxide, resulting in an enrichment of covalently bonded $\mathrm{V}^{5+}$ species and surface hydroxylation. A small change in the surface potential barrier induced by wet propane oxidation feed can contribute to a modification of the bulk-surface charge transfer and improved selectivity to acrylic acid.

\section{INTRODUCTION}

Complex mixed oxides like $\mathrm{MoVTeNbO}_{\mathrm{x}}$ in the orthorhombic M1 phase (ICSD 55097) $)^{1,2}$ have attracted much interest as promising catalysts for selective oxidation reactions, in particular for the (amm)-oxidation of propane. ${ }^{3-5}$ The active surface layer of $\mathrm{MoVTeNbO}_{\mathrm{x}}$ is composed of vanadium oxide nanodomains, which are separated from each other by $\mathrm{Mo}_{\mathrm{x}} \mathrm{O}_{\mathrm{y}}$ and $\mathrm{Te}_{\mathrm{x}} \mathrm{O}_{\mathrm{y}}$ moieties, on top of the redox-active crystalline bulk. ${ }^{6-8}$ This termination layer is likely adapting its electronic structure and composition to the chemical potential of the surrounding atmosphere. $6,7,9$ Indeed, changes in the surface layer on $\mathrm{MoVTeNbO}_{\mathrm{x}}$ were observed under reaction conditions together with a change in band bending $\left(e \Delta V_{s}\right.$, with $V_{s}$ being the potential at the surface), which also affects the electrical conductivity of the n-type semiconductor. ${ }^{10}$ The acrylic acid formation over $\mathrm{MoVTeNbO}_{\mathrm{x}}$ is enhanced by the addition of water vapor to the gas feed. ${ }^{8}$ Steam was shown to modify the valence band spectra and the work function as well, and it causes a higher average vanadium oxidation state and a decreased electrical conductivity. ${ }^{11}$

Recently, the tellurium- and niobium-free MoV-oxide in the M1 phase has been shown to be able to produce acrylic acid as well, albeit with diminished selectivity compared to MoVTeN$\mathrm{bO}_{\mathrm{x}}{ }^{4,12}$ Differences in the occupation of the hexagonal channels in the M1 crystal structure between the two mixed-metal oxides are also reflected in differences in the surface layer formed under catalytic operation conditions, where an accumulation of vanadium is observed on $\mathrm{MoV}$-oxide and of tellurium on MoVTeNb-oxide. ${ }^{12}$ The semiconducting properties of MoVoxide and the influence of steam on its surface electronic structure and electrical conductivity are still not known. Microwave cavity perturbation techniques (MCPT) provide a sensitive and noninvasive tool to study the dielectric properties (complex permittivity) and the electrical conductivity of semiconductors $^{13,14}$ under operando conditions and in a contact-free fashion, thus avoiding erroneous results caused by electrode-sample contact problems. ${ }^{14-16}$

In this study, we investigated the electronic properties of MoV-oxide (M1 phase) and their possible relation to its catalytic performance. The complex permittivity and electrical conductivity of MoV-oxide were studied under catalytic operation conditions in the oxidation of light alkanes from ethane to $n$ butane based on the MCPT. These measurements were complemented by synchrotron-based near-ambient-pressure $\mathrm{X}$-ray photoelectron spectroscopy (NAP-XPS) in the same gas feeds, which give information about the surface electronic structure and surface composition. Moreover, the effect of steam not only on the catalytic performance, but also on the conductivity or permittivity of MoV-oxide and its surface electronic structure was analyzed.

Received: February 8, 2019

Revised: April 20, 2019

Published: April 29, 2019 


\section{EXPERIMENTAL SECTION}

Catalyst. The MoV-oxide sample in the orthorhombic M1 phase (internal ID 18075) was prepared by a hydrothermal synthesis method as described previously. ${ }^{12}$ The hydrothermal product was treated under an argon flow of $100 \mathrm{~mL} / \mathrm{min}$ for $2 \mathrm{~h}$ at $400{ }^{\circ} \mathrm{C}$ (heating rate, $10 \mathrm{~K} / \mathrm{min}$ ), resulting in a phase-pure, crystalline $\mathrm{MoV}$-oxide catalyst.

The sample exhibits a total surface area of $27.9 \mathrm{~m}^{2} / \mathrm{g}$ determined from the isothermal adsorption of nitrogen at -196 ${ }^{\circ} \mathrm{C}$ (Quantachrome Autosorb-6-B) with a micropore surface area of $18.1 \mathrm{~m}^{2} / \mathrm{g}$ and external surface area of $9.8 \mathrm{~m}^{2} / \mathrm{g}$. Detailed structural information based on a single-crystal structural analysis complemented by scanning electron microscopy and scanning transmission electron microscopy can be found in a previous study, ${ }^{12}$ showing phase purity of the catalyst composed of the orthorhombic M1 structure (ICSD 55097). ${ }^{1,2}$ No structural changes occur during the operando experiments (Figure S1). Energy-dispersive X-ray spectroscopy (EDX) was conducted using the Hitachi S-4800 spectrometer with an EDAX detector at $15 \mathrm{kV}$, showing a metal content of 29.5 at \% vanadium and 70.5 at \% molybdenum.

Microwave Cavity Perturbation Technique (MCPT). Contact-free and operando electrical conductivity and permittivity measurements were performed based on the microwave cavity perturbation technique. ${ }^{14,17}$ The MCPT relies on a perturbation of the resonator properties of a microwave cavity (cylindrical resonator with a radius of $22.5 \mathrm{~mm}$ and height of 20 $\mathrm{mm}$; transverse magnetic $\mathrm{TM}_{010}$ mode at $5 \mathrm{GHz}$ ) by the semiconducting sample. ${ }^{14,18}$ The sample was placed in the electric field antinode in the center of the resonator. To obtain the unloaded quality factor $Q$ of the cavity, the measured reflection coefficient $\Gamma(\omega)$, which was recorded with an Agilent PNA-L N5230C vector network analyzer, was fitted with the QOREFL program. ${ }^{19}$ Further experimental details are provided in the Supporting Information (SI). The perturbation was related to the relative complex permittivity $\tilde{\varepsilon}=\varepsilon^{\prime}-i \varepsilon^{\prime \prime}$ of the sample, ${ }^{13,14}$ as described before. ${ }^{20}$ The Landau-LifshitzLooyenga effective medium approach was used to obtain the bulk permittivity values. ${ }^{21-23}$ Finally, the electrical conductivity $\sigma$ was determined from the imaginary part of the permittivity $\varepsilon^{\prime \prime}$ and the angular resonant frequency $\omega$ according to ${ }^{13,14}$

$$
\sigma=\varepsilon_{0} \omega \varepsilon^{\prime \prime}
$$

where $\varepsilon_{0}$ denotes the vacuum permittivity. The dielectric properties given by the (frequency-dependent) permittivity or dielectric function describe the response of a sample to the driving electromagnetic field, which stems from the displacement of bound and free charges or dipole alignment. ${ }^{13}$ The present study is concerned with the interaction with the electric field component of the microwave analyzing changes in $\tilde{\varepsilon}$ of MoV-oxide, and not with the magnetic field as described by the complex permeability of a sample. ${ }^{13}$ In the frequency domain, the permittivity is a complex function, where the real part $\left(\varepsilon^{\prime}\right)$ is associated with energy storage, and the imaginary part $\left(\varepsilon^{\prime \prime}\right)$ with energy dissipation or loss. ${ }^{13}$ While both a dipolar response and the response of mobile charge carriers contribute to the dielectric behavior, ${ }^{24}$ it is assumed that the imaginary part of the permittivity or the electrical conductivity (i.e., the dissipative contributions; eq 1) are dominated by charge carriers in the case of semiconductors investigated in the microwave frequency range. $^{13}$
To study the temperature dependence of the conductivity, the sample was first heated to $270{ }^{\circ} \mathrm{C}$ in the respective gas feed and kept for $1 \mathrm{~h}$ at this temperature, and then it was cycled between low and high temperatures $\left(270{ }^{\circ} \mathrm{C}\right.$ (no. 1) $\rightarrow 200 \rightarrow 290 \rightarrow$ $230 \rightarrow 270$ (no. 2$) \rightarrow 250^{\circ} \mathrm{C}$ ). Data analysis was performed as described in ref 20 .

The simultaneous analysis of reactant and product gases in the oxidation of light alkanes with a gas feed composition of $3 \%$ alkane (ethane, propane, $n$-butane) and $6 \% \mathrm{O}_{2}$ in $\mathrm{N}_{2}$ at $270{ }^{\circ} \mathrm{C}$ (heating rate $2 \mathrm{~K} / \mathrm{min}$ ) was performed by online gas chromatography (GC, Agilent 7890). The influence of water was analyzed by adding $5 \%$ steam to the propane oxidation feed. The catalyst was measured at contact times $(W / F)$ ranging from 0.13 to $1.63(\mathrm{~g} \cdot \mathrm{s}) / \mathrm{mL}$ (weight $W=44-54 \mathrm{mg} \mathrm{MoVO}_{\mathrm{x}}$, total gas flow $F=2-20 \mathrm{~mL} / \mathrm{min}$ ) and at temperatures from 200 to 290 ${ }^{\circ} \mathrm{C}$. Alkane conversion $(X)$ and product selectivity $(S)$ were calculated according to the following formulas

$$
\begin{aligned}
X & =\frac{c_{\text {ref }}(\text { alkane })-c(\text { alkane })}{c_{\text {ref }}(\text { alkane })} \\
S_{i} & =\frac{N_{\text {carbon }, i} c_{i}}{\sum_{j}^{\text {products }} N_{\text {carbon }, j} \cdot c_{j}}
\end{aligned}
$$

Here, $c_{i}$ denotes the concentration of species $i, N$ denotes the corresponding number of carbon atoms, and the subscript "ref" refers to measurement at room temperature.

Near-Ambient-Pressure X-ray Photoelectron Spectroscopy (NAP-XPS). NAP-XPS measurements were performed at the ISISS (Innovative Station for In Situ Spectroscopy) beam line at the synchrotron radiation source BESSY II in Berlin, Germany. A pressed powder pellet of $13 \mathrm{mg} \mathrm{MoV}$-oxide (ID 18075) was measured at $270{ }^{\circ} \mathrm{C}$ (heating rate, $5 \mathrm{~K} / \mathrm{min}$ ) and $25 \mathrm{~Pa}$ in 1:2 mixtures of alkane $/ \mathrm{O}_{2}(1 \mathrm{~N} \mathrm{~mL} / \mathrm{min} / 2 \mathrm{~N} \mathrm{~mL} /$ min, alkane $=$ ethane, propane, $n$-butane $)$ and in a wet propane oxidation feed $\left(0.37 \mathrm{~N} \mathrm{~mL} / \mathrm{min}\right.$ propane $/ 0.74 \mathrm{~N} \mathrm{~mL} / \mathrm{min} \mathrm{O}_{2} /$ 4.9 $\mathrm{N} \mathrm{mL} / \mathrm{min} \mathrm{H}_{2} \mathrm{O}$ ). The gas phase was monitored using a Varian CP-4900 Micro gas chromatograph (Micro-GC) and an IONICON proton-transfer-reaction mass spectrometer (PTRMS).

The measurements were carried out at different photoelectron kinetic energies $\left(E_{\text {kin }}\right)$ probing the "surface" region with an approximate electron inelastic mean free path length $\lambda_{\text {IMFP }}$ of $0.6 \mathrm{~nm}\left(E_{\mathrm{kin}} \approx 144-163 \mathrm{eV}\right.$ using photon energies $E_{h v}$ of $380 \mathrm{eV}$ (Mo 3d) and $680 \mathrm{eV}(\mathrm{V} 2 \mathrm{p}, \mathrm{O} 1 \mathrm{~s})$ ) and at greater probing depths with $\lambda_{\text {IMFP }}$ of $1.7 \mathrm{~nm}\left(E_{\mathrm{kin}} \approx 744-763 \mathrm{eV}\right.$ using photon energies $E_{h v}$ of $980 \mathrm{eV}(\mathrm{Mo} \mathrm{3d})$ and $1280 \mathrm{eV}(\mathrm{V} 2 \mathrm{p}, \mathrm{O} 1 \mathrm{~s})$ ). The values of $\lambda_{\text {IMFP }}$ were estimated using the predictive TPP-2M formula by Tanuma, Powell, and Penn ${ }^{25,26}$ (NIST Electron Inelastic-MeanFree-Path Database version 1.2). ${ }^{27}$ For the quantitative analysis of the core levels, atomic subshell photoionization cross sections and asymmetry parameters from numerical calculations by Yeh and Lindau ${ }^{28,29}$ were used taking the photon-energy-dependent photon flux into account.

The core-level spectra were deconvoluted using GaussianLorentzian product functions after subtracting a Shirley background with the CasaXPS software (Neal Fairley, version 2.3.15, 1999-2009 Casa Software Ltd.).

To determine the work function $\Phi$ of the sample, the secondary electron cutoff was measured with a bias of $-17.8 \mathrm{~V}$ applied to the sample at a photon energy of $100 \mathrm{eV}$ and a pass energy of $2 \mathrm{eV}$. The position of the cutoff was determined by a linear extrapolation between 20 and $80 \%$ of the maximum 
intensity. The valence band (VB) onset was likewise evaluated by a leading-edge extrapolation using a photon energy of $100 \mathrm{eV}$.

Catalytic Test in a Fixed-Bed Reactor. Oxidations of ethane and propane were measured at atmospheric pressure in a parallel reactor equipped with 10 fixed-bed quartz reactors (inner diameter, $2 \mathrm{~mm}$ ). ${ }^{30}$ The catalysts were pressed under $\sim 1.25 \mathrm{MPa}$, crushed, and sieved to a particle size of 150-200 $\mu \mathrm{m}$. The catalyst mass was $40 \mathrm{mg}$, and the total flow was $6.7 \mathrm{~mL} /$ min, resulting in $W / F=0.36(\mathrm{~g} \cdot \mathrm{s}) / \mathrm{mL}$. The temperature was varied between 250 and $300{ }^{\circ} \mathrm{C}$. The feed was composed of $3 \%$ $\mathrm{C}_{n} \mathrm{H}_{2 n+2}, 6 \% \mathrm{O}_{2}$, and $91 \% \mathrm{~N}_{2}$. Products were analyzed using an online gas chromatograph (Agilent 7890A) equipped with a combination of Plot-Q (length, $30 \mathrm{~m}$; internal diameter, 0.53 $\mathrm{mm}$; film thickness, $40 \mu \mathrm{m}$ ) and Plot-MoleSieve 5A columns (length, $30 \mathrm{~m}$; internal diameter, $0.53 \mathrm{~mm}$; film thickness, 50 $\mu \mathrm{m})$, connected to a thermal conductivity detector for analysis of the permanent gases $\mathrm{CO}, \mathrm{CO}_{2}, \mathrm{~N}_{2}, \mathrm{O}_{2}$, and $\mathrm{CH}_{4}$. A system of an FFAP (length, $30 \mathrm{~m}$; internal diameter, $0.53 \mathrm{~mm}$; film thickness, $1 \mu \mathrm{m}$ ) and a Plot-Q column (length, $30 \mathrm{~m}$; internal diameter, $0.53 \mathrm{~mm}$; film thickness, $40 \mu \mathrm{m}$ ), connected to a flame ionization detector was used to analyze C2-C3 hydrocarbons and oxygenates.

\section{RESULTS}

Influence of Carbon Number of Alkane Molecule and Redox Potential in Alkane Oxidation. The electronic properties of MoV-oxide and catalytic performance in ethane, propane, and $n$-butane oxidation were studied simultaneously in operando experiments in mixtures of alkane and oxygen in a ratio of $1: 2$, which is typically applied in selective oxidation reactions. The conductivity values presented in Figure la were measured in a broad conversion range without addition of steam to the feed. The corresponding product selectivity-conversion
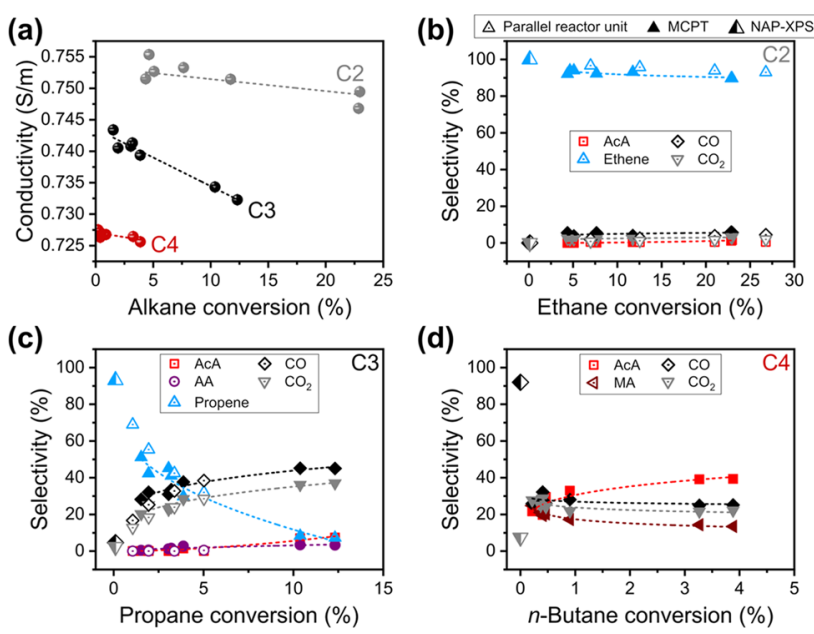

Figure 1. Conductivity of $\mathrm{MoV}$-oxide as a function of alkane conversion in $3 \%$ ethane/propane/ $n$-butane and $6 \% \mathrm{O}_{2}$ in $\mathrm{N}_{2}$ at $270{ }^{\circ} \mathrm{C}$, ambient pressure of $1 \times 10^{5} \mathrm{~Pa}$, and different contact times of $0.13-1.6(\mathrm{~g} \cdot \mathrm{s}) /$ $\mathrm{mL}$ (a), and conversion and selectivity (filled symbols) in ethane oxidation (b), propane oxidation (c), and $n$-butane oxidation (d) measured simultaneously in the MCPT reactor. Selectivity and conversion measured at low pressure $(25 \mathrm{~Pa})$ in the NAP-XPS cell (half-filled symbols) as well as recorded in a parallel catalyst testing setup (open symbols; $1 \times 10^{5} \mathrm{~Pa}, 250-300{ }^{\circ} \mathrm{C}, 0.36(\mathrm{~g} \cdot \mathrm{s}) / \mathrm{mL}$ ) are shown for comparison. The products were ethene, propene, acrylic acid (AA), acetic acid (AcA), maleic anhydride (MA), $\mathrm{CO}$, and $\mathrm{CO}_{2}$; product symbols are assigned in the legend.
$(S-X)$ graphs are shown in Figure $1 \mathrm{~b}-\mathrm{d}$. The filled symbols correspond to data measured in the MCPT reactor at ambient pressure $\left(1 \times 10^{5} \mathrm{~Pa}\right)$. The half-filled symbols at low alkane conversion were recorded during the NAP-XPS measurements at reduced total pressure $(25 \mathrm{~Pa})$. For comparison, the catalytic performance of $\mathrm{MoV}$-oxide measured in a fixed-bed catalytic testing setup (parallel reactor unit with tubular reactors in continuous-flow mode ${ }^{30}$ ) is shown in addition in Figure $1 \mathrm{~b}-\mathrm{c}$ (open symbols) demonstrating clearly that the conductivity measurements were performed under realistic, i.e., real operando, conditions. A comparison of $\mathrm{MoV}$-oxide to the performance of MoVTeNb-oxide can be found in the Supporting Information (Figure S18).

MoV-oxide was most active in ethane oxidation and least active in $n$-butane oxidation. Ethene was formed with a high selectivity $(\geq 90 \%)$ over the entire range of investigated conversions in oxidative dehydrogenation of ethane. The catalyst was less selective in the oxidation of propane, where the propene selectivity significantly decreased at higher conversions in favor of $\mathrm{CO}, \mathrm{CO}_{2}$, acetic acid (AcA), and acrylic acid (AA), which are the major side products. No olefin, but only oxygenates were detected in $n$-butane oxidation. The predominating products were acetic acid, $\mathrm{CO}, \mathrm{CO}_{2}$, and maleic anhydride (MA). A good agreement of the data recorded in the operando MCPT setup (filled symbols) with catalytic performance data measured in a parallel reactor catalyst testing setup (open symbols) was observed. The selectivity to olefins and carbon oxides in alkane oxidation at low pressure in the NAP-XPS experiments (half-filled symbols in Figure $1 b-d$ ) was in line with the general trends of the $S-X$ trajectories measured in the MCPT cell when extrapolating to low conversions. However, no acids were detectable perhaps due to sticking of the polar products to the cold walls of the operando NAP-XPS cell or on the catalyst surface.

The conductivity of MoV-oxide decreased with increasing alkane chain length in the order ethane $>$ propane $>n$-butane, i.e., when the feed became more reducing (Figure 1a). The raw data are presented in Figures S2 and S3. Similarly, a conductivity decrease was observed by reducing the oxygen content in propane oxidation feed (Figure S4). Another batch (ID 20000) of $\mathrm{MoV}$-oxide was used in the latter experiment. MoVTeNboxide showed an opposite behavior with an increase in conductivity from ethane to $n$-butane oxidation gas feeds and also with an increased reduction potential of gas feeds with different propane $/ \mathrm{O}_{2}$ ratios, which was interpreted as n-type semiconducting behavior. ${ }^{10}$ The finding of an opposite conductivity response suggests that $\mathrm{MoV}$-oxide is a p-type semiconductor with holes being the majority charge carriers.

Previous operando MCPT measurements showed a positive correlation between the reactant conversion and the conductivity for the n-type semiconductor $\mathrm{V}_{2} \mathrm{O}_{5},{ }^{20}$ and a negative correlation for the p-type semiconductor vanadyl pyrophosphate $(\mathrm{VPP})^{20,31}$ associated with an increased degree of reduction at higher conversions. In agreement with this, the conductivity of MoV-oxide decreased at higher alkane conversions.

To further investigate the electrical transport mechanism in $\mathrm{MoV}$-oxide, the temperature dependence of the conductivity was measured. Figure 2 presents the logarithm of the conductivity $(\ln (\sigma))$ of MoV-oxide in steady state as a function of the reciprocal temperature $(1 / T)$, and the inset shows the apparent activation energies of conduction $\left(E_{c}\right)$ in the different gas feeds from the slope of the Arrhenius-type plot. 


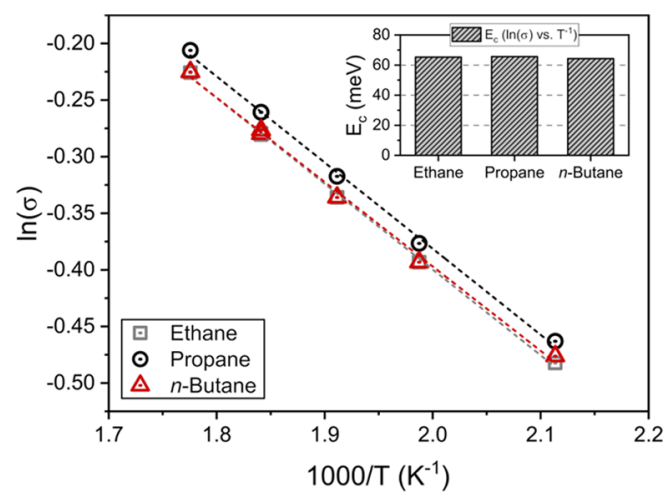

Figure 2. Temperature dependence of conductivity of MoV-oxide (3\% ethane/propane/ $n$-butane, $6 \%$ oxygen in $\mathrm{N}_{2}$ ). The inset shows the Arrhenius-type apparent activation energy of conduction.

Experimental details are documented in Supporting Information Figures S5-S8.

The conductivity of MoV-oxide increased approximately linearly with temperature in the investigated range. The offset of the conductivity in the propane oxidation gas feed could be caused by a difference in the microwave coupling since the temperature-dependent measurements correspond to individual measurements on subsequent days. The Arrhenius-type apparent activation energy of conduction $\left(E_{c}\right)$ shown in the inset of Figure 2 was similar in the different gas feeds and amounts to about $0.06 \mathrm{eV}$. The small activation energy indicates a barrier of an activated hopping conduction mechanism or an excitation to (from) a defect level in the band gap of the semiconductor in agreement with the microstructure of MoVoxide. $^{32}$

The redox response and the surface composition of MoVoxide under different alkane oxidation conditions (ethane, propane, $n$-butane oxidation feeds) were complementarily investigated by operando NAP-XPS (Figure 3). The core-level spectra (Figure S9) were measured at two probing depths with estimated inelastic mean free path lengths $\lambda_{\mathrm{IMFP}}$ of 0.6 and 1.7 $\mathrm{nm}$. Fit parameters and example fits are presented in Table S1 and Figure S10, respectively. The different alkanes exhibited practically no influence on the surface composition (Figure $\mathrm{S} 11)$. The $\mathrm{V} / \mathrm{Mo}$ ratio increased only very slightly with increasing alkane chain length in the order ethane $<$ propane $<n$-butane. Vanadium atom \% values of $23.5 \pm 0.3 \%$ in $\mathrm{C}_{2} \mathrm{H}_{6} /$ $\mathrm{O}_{2}, 24.2 \pm 0.1 \%$ in $\mathrm{C}_{3} \mathrm{H}_{8} / \mathrm{O}_{2}$, and $24.6 \pm 0.1 \%$ in $\mathrm{C}_{4} \mathrm{H}_{10} / \mathrm{O}_{2}$ were observed (average value \pm 1 standard deviation). In the dry alkane oxidation feeds, the average vanadium oxidation state was $\sim 4.3$ in the surface-sensitive $V 2 \mathrm{p}_{3 / 2}$ measurements $\left(\lambda_{\text {IMFP }}\right.$ of 0.6 $\mathrm{nm})$ as well as in deeper layers $\left(\lambda_{\text {IMFP }}\right.$ of $1.7 \mathrm{~nm}$ ) (Figures $3 \mathrm{a}$ and S12). In the case of molybdenum, no considerable changes in the Mo 3d core levels were found (Figure S9), indicating predominant molybdenum $6+$ oxidation state with a $3 d_{5 / 2}$ binding energy of $232.7 \mathrm{eV}$ and an energy difference between Mo $3 \mathrm{~d}_{3 / 2}$ and Mo $3 \mathrm{~d}_{5 / 2}$ of $3.1 \mathrm{eV}$, in agreement with literature data of the spin-orbit splitting in Mo-oxides. ${ }^{33,34}$

The constant average oxidation state was in agreement with the constant area of the peak above the valence band onset at a binding energy $\left(E_{\text {bind }}\right)$ of $\sim 1.6 \mathrm{eV}$ (Figure $3 \mathrm{~b}$ ), which is characteristic for occupied V $3 \mathrm{~d}$ states; see vanadium oxides with $3 \mathrm{~d}$ electrons, including nonstoichiometric $\mathrm{V}_{2} \mathrm{O}_{5-x},{ }^{35,36}$ vanadyl pyrophosphate, ${ }^{37}$ and $\mathrm{MoVTeNbO}_{\mathrm{x}}{ }^{10,11,38}$ Additionally, also Mo $4 \mathrm{~d}$ states can contribute to the peak, e.g., in defective $\mathrm{MoO}_{3-x}{ }^{38-41}$
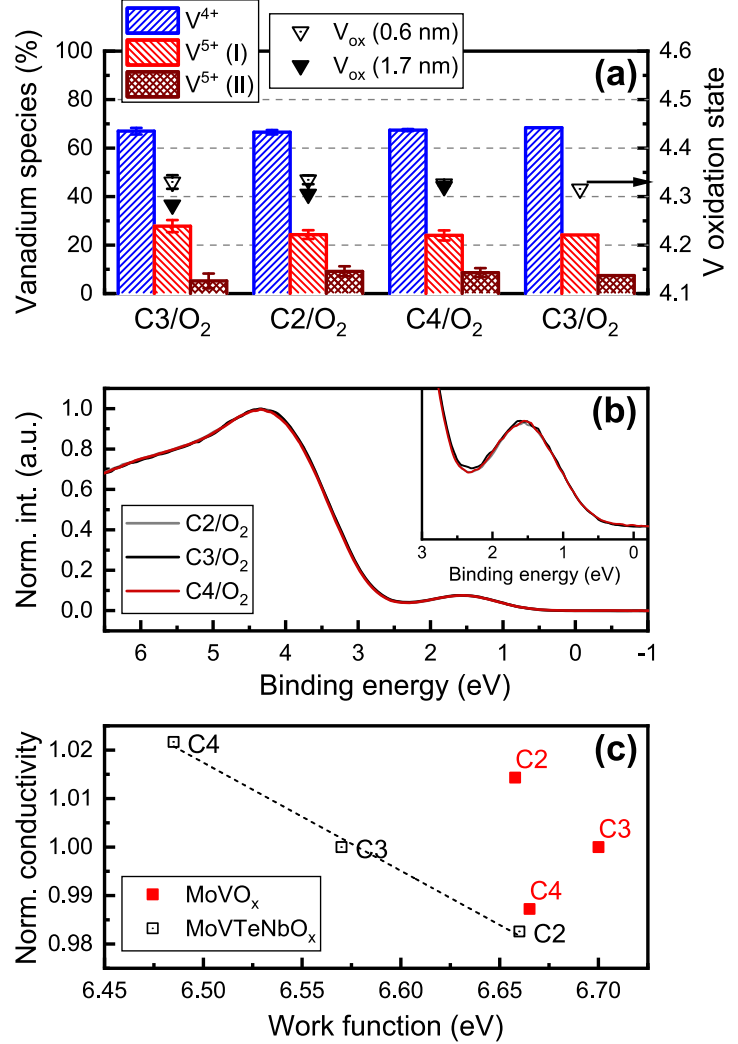

Figure 3. Relative amount of $V$ species determined from a fit of $V 2 p_{3 / 2}$ core level with one 4+ and two $5+$ components and vanadium oxidation state $V_{\text {ox }}$ at $\lambda_{\text {IMFP }}=0.6$ and $1.7 \mathrm{~nm}$, respectively (a); evolution of $V 3 \mathrm{~d}$ / Mo $4 \mathrm{~d}$ peak area of $\mathrm{MoV}$-oxide as a function of time on stream (25 Pa, $270{ }^{\circ} \mathrm{C}, E_{h v}$ of $100 \mathrm{eV}$ ) in different dry gas feeds as shown in the legend (b); and conductivity of $\mathrm{MoV}$-oxide as a function of the work function in different dry gas feeds (c). The data of $\mathrm{MoVTeNbO}_{\mathrm{x}}$ shown for comparison were taken from our previous publication ${ }^{10}$ (adapted with permission from Heine, C.; Hävecker, M.; Sanchez-Sanchez, M.; Trunschke, A.; Schlögl, R.; Eichelbaum, M. Work Function, Band Bending, and Microwave Conductivity Studies on the Selective Alkane Oxidation Catalyst MoVTeNb-Oxide (Orthorhombic M1 Phase) under Operation Conditions. J. Phys. Chem. C 2013, 117, 2698826997. Copyright 2013 American Chemical Society).

The work function of MoV-oxide was found to be about 6.7 $\mathrm{eV}$ in the dry alkane oxidation gas feeds (Figures $3 \mathrm{c}$ and S13). This is similar to the work functions of $\mathrm{MoVTeNbO}_{\mathrm{x}}$ (M1) $(6.3-6.7 \mathrm{eV}),{ }^{10,11}$ vanadyl pyrophosphate $(6.8-6.9 \mathrm{eV}),{ }^{37,42}$ and $\mathrm{V}_{2} \mathrm{O}_{5}(6.5-6.6 \mathrm{eV})$ determined in the same way, or of $\mathrm{MoO}_{3}$ $(6.86 \mathrm{eV})$ determined with ultraviolet photoelectron spectroscopy (UPS).$^{43}$ In the dry ethane/propane/ $n$-butane oxidation gas feeds, only small changes of the work function of MoV-oxide and no trend were observed, whereas in the case of MoVTeNboxide, the conductivity and work function are correlated in a linear way (Figure $3 \mathrm{c}$ ). ${ }^{10}$

The impact of alkane molecule chain length, alkane-to-oxygen ratio, and contact time on conductivity and surface electronic properties of $\mathrm{MoV}$-oxide in alkane oxidation experiments in dry feeds can be summarized as follows:

1. The conductivity decreases with increasing carbon number in the alkane molecule, increasing contact time, and decreasing oxygen concentration in the feed, i.e., with increasing reduction potential of the gas feed. The behavior is typical for a p-type semiconductor. 

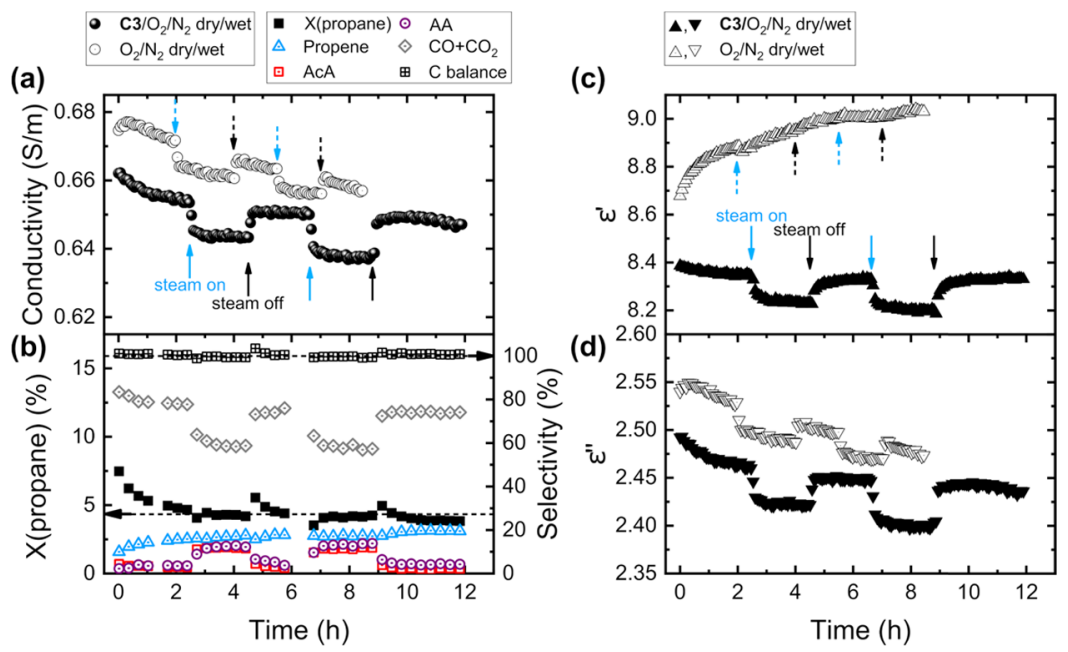

Figure 4. $\mathrm{MoV}$-oxide in $3 \%$ propane, $6 \% \mathrm{O}_{2}, 0$ or $5 \% \mathrm{H}_{2} \mathrm{O}$ in $\mathrm{N}_{2}$ at $270{ }^{\circ} \mathrm{C}$ and similar propane conversions with $W / F=0.80(\mathrm{~g} \cdot \mathrm{s}) / \mathrm{mL}(\mathrm{dry})$ and 0.28 $(\mathrm{g} \cdot \mathrm{s}) / \mathrm{mL}$ (wet) (filled symbols) and reference experiment in $6 \% \mathrm{O}_{2}$ and 0 or $5 \% \mathrm{H}_{2} \mathrm{O}$ in $\mathrm{N}_{2}$ (open symbols): (a) conductivity changes, (b) catalytic performance (propane conversion $X$; selectivity to propene, acetic acid (AcA), acrylic acid (AA), sum of $\mathrm{CO}$ and $\mathrm{CO}_{2}$, and carbon balance), (c) response of the real part of permittivity $\varepsilon^{\prime}$, and (d) response of the imaginary part of permittivity $\varepsilon^{\prime \prime}$.

2. The temperature dependence of the conductivity suggests a hopping conduction mechanism or a charge carrier excitation from defect levels.

3. Surface composition, average surface oxidation state, abundance of occupied d states, and work function do not change with chain length of the hydrocarbon molecule, i.e., no measurable change in the surface potential barrier height ( $e \Delta V s$, band bending) depending on the gas-phase composition was observed.

Influence of Steam in Propane Oxidation. The addition of steam to the gas feed has beneficial effects in propane oxidation to acrylic acid over MoV-based oxides, since both the propane conversion and the selectivity to acrylic acid are increased. ${ }^{8}$ The effect of steam on the semiconducting properties of $\mathrm{MoV}$-oxide was analyzed by switching between "dry" $\left(3 \% \mathrm{C}_{3} \mathrm{H}_{8} / 6 \% \mathrm{O}_{2}\right.$ in $\left.\mathrm{N}_{2}\right)$ and "wet" $\left(3 \% \mathrm{C}_{3} \mathrm{H}_{8} / 6 \% \mathrm{O}_{2} / 5 \%\right.$ $\mathrm{H}_{2} \mathrm{O}$ in $\mathrm{N}_{2}$ ) propane oxidation gas feeds and monitoring the MCPT conductivity (Figure 4a, filled symbols), the catalytic performance at $270{ }^{\circ} \mathrm{C}$ (Figure $4 \mathrm{~b}$ ) and the permittivity (Figure $4 \mathrm{c}, \mathrm{d}$, filled symbols). The total gas flow was adjusted to investigate the response of $\mathrm{MoV}$-oxide at similar propane conversions of $3.2-4.8 \%$. The results of contact time variation in the presence of steam at $270{ }^{\circ} \mathrm{C}$, in which the conversion was changed between 2 and $15 \%$ in analogy to the experiments in dry feed shown in Figure 1, are presented in Figure S14. Furthermore, a reference experiment was conducted by switching between dry and wet $\mathrm{O}_{2} / \mathrm{N}_{2}$ gas feeds to determine the effect of steam on the MCPT results without an additional conversion of propane over MoV-oxide (Figure 4a,c,d, open symbols).

The conductivity and permittivity of MoV-oxide decreased in the presence of steam (Figures $4 \mathrm{a}$ and S14a). Part of the effect of steam on the conductivity (and the imaginary part of the permittivity, Figure 4d) is caused by MoV-oxide and water vapor alone; see the reference experiment in Figure 4a,d. However, the real part of the permittivity $\varepsilon^{\prime}$ steadily increased with time in the reference experiment without any pronounced drop when introducing $\mathrm{H}_{2} \mathrm{O}(\mathrm{g}$ ) (Figure $4 \mathrm{c}$ ) approaching almost steady state after $6 \mathrm{~h}$. Apparently, MoV-oxide responds differently to steam in the gas phase in the presence or absence of propane. It should also be mentioned that the measurement of the empty reactor using the same experimental protocol, which is always required for determining the "unperturbed" quality factor $Q_{0}$ and resonant frequency $\omega_{0}$ of the microwave cavity, showed no response to the dry/wet cycles, thus excluding gas phase $\mathrm{H}_{2} \mathrm{O}$ to be the reason for the observed MCPT response.

A slight deactivation was observed during the dry/wet cycles and a small change in the product selectivity (Figure $4 \mathrm{~b}$ ), which could explain the not entirely reversible changes of the conductivity and of $\varepsilon^{\prime \prime}$. The influence of steam on the catalytic performance of MoV-oxide from the operando MCPT experiments is in agreement with the literature in terms of an increased selectivity to the acids mainly at the expense of $\mathrm{CO}$ and $\mathrm{CO}_{2}$ (Figures $4 \mathrm{~b}$ and $\mathrm{S} 14 \mathrm{~b}, \mathrm{c}$ ) as well as an increased activity (Figure $\mathrm{S} 14 \mathrm{~b}, \mathrm{c}){ }^{12}$ which is qualitatively similar to the findings for MoVTeNb-oxide. ${ }^{8}$

The addition of steam to the feed caused major changes in average vanadium oxidation state (Figure 5a) and surface composition (Figure 5b), as measured by NAP-XPS. In dry feed, $\sim 24 \% \mathrm{~V}$ and $\sim 76 \%$ Mo were found, while the concentration of vanadium increased in wet propane feed, leading to $33 \% \mathrm{~V}$ and $67 \%$ Mo after the treatment (Figure 5b). The increase came to a halt by keeping the catalyst after the wet experiment for some time in dry feed. Deeper layers of MoV-oxide were less sensitive to the steam content in the feed (Figure 5b, open symbols).

The average vanadium oxidation state increased from 4.3 to 4.4 in the surface-sensitive V $2 \mathrm{p}_{3 / 2}$ measurements (Figure 5a). No changes were observed in deeper layers $\left(\lambda_{\text {IMFP }}=1.7 \mathrm{~nm}\right)$, where a lower average oxidation state of $\sim 4.3$ was measured. A constrained fit model was applied using one 4+ component and two $5+$ components (Table S1), where the second $\mathrm{V}^{5+}(\mathrm{II})$ species was ascribed to surface vanadium species originating from the migration out of the hexagonal channels in the M1 crystal structure (M12 position). ${ }^{12}$ Most notably, the addition of steam leads to a change of the relative amount of the two $\mathrm{V}^{5+}$ components with the $\mathrm{V}^{5+}$ (II) species becoming the prominent $5+$ species (Figure 5a), which is in agreement with previous findings for MoV-oxide (M1), ${ }^{12}$ MoVTeNb-oxide (M1), ${ }^{12}$ and vanadyl pyrophosphate. ${ }^{42}$ The changes in the core-level spectra were irreversible, i.e., reapplying the dry propane oxidation gas feed did not significantly decrease the $\mathrm{V}^{5+}$ (II) contribution in 


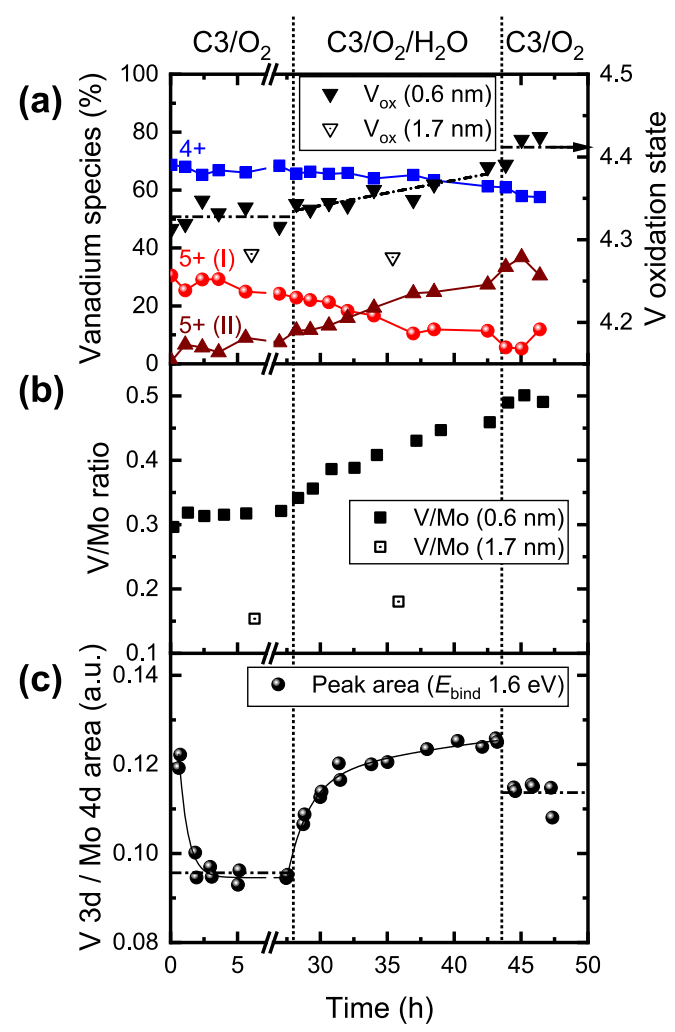

Figure 5. Relative amount of $\mathrm{V}$ species determined from a fit of the $\mathrm{V}$ $2 \mathrm{p}_{3 / 2}$ core level with one $4+$ and two $5+$ components and vanadium oxidation state $\mathrm{V}_{\text {ox }}$ at $\lambda_{\text {IMFP }}=0.6$ and $1.7 \mathrm{~nm}$, respectively (a); evolution of the $\mathrm{V} / \mathrm{Mo}$ ratio at $\lambda_{\mathrm{IMFP}}=0.6$ and $1.7 \mathrm{~nm}$, respectively, (b); and evolution of $\mathrm{V} \mathrm{3d} / \mathrm{Mo} 4 \mathrm{~d}$ peak area $\left(E_{h v}\right.$ of $\left.100 \mathrm{eV}\right)(\mathrm{c})$ by changing from dry propane $/ \mathrm{O}_{2}(1: 2)$ feed to wet propane $/ \mathrm{O}_{2} / \mathrm{H}_{2} \mathrm{O}$ feed and back to dry feed at $270{ }^{\circ} \mathrm{C}$ and $25 \mathrm{~Pa}$ total pressure.

the period of the experiment, which was comparatively short (Figure 5a).

The V 3d/Mo 4d peak area decreased rapidly after contact of the fresh catalyst with dry propane and oxygen, and increased again in the steam-containing $\mathrm{C}_{3} \mathrm{H}_{8} / \mathrm{O}_{2} / \mathrm{H}_{2} \mathrm{O}$ gas feed pointing toward an increased occupancy of the metal d states (Figure 5c). The observation is in apparent contradiction to the oxidation of the surface in wet feed observed by analysis of the core-level spectra (Figure 5a). Under the assumption of a homogeneous sample, the disagreement might point to the involvement of oxygen $2 p$ states in the valence band near the Fermi level and suggests substantial covalent bonding contributions of the corresponding $\mathrm{V}-\mathrm{O}$ bonds, which are affected by the chemical changes taking place on the surface in the presence of steam. For defective $\mathrm{VSbO}_{4}$, it has been shown that $2 \mathrm{p}$ states of oxygen atoms located near a vanadium vacancy present a sharp peak at 1 $\mathrm{eV}^{44}$

The work function decreased clearly by $200 \mathrm{meV}$ between the dry $\mathrm{C}_{3} \mathrm{H}_{8} / \mathrm{O}_{2}$ and wet $\mathrm{C}_{3} \mathrm{H}_{8} / \mathrm{O}_{2} / \mathrm{H}_{2} \mathrm{O}$ feed (Figure $\mathrm{S} 13$ ). The valence band onset (Figures $6 \mathrm{~b}, \mathrm{~S} 15$, and S16) and the core-level binding energies (Figures S9 and S15) shift to a much smaller extent, but consistently to higher energies by $50 \mathrm{meV}$, suggesting a change in band bending $\left(e \Delta V_{s}\right)$ induced by the wet propane oxidation feed. Hence, it is assumed that the work function changes $(\Delta \Phi)$ in the steam-containing gas feed are dominated by changes of the electron affinity $(\Delta \chi)$ according to $\Delta \Phi=\Delta \chi-$ $e \Delta V_{\mathrm{s}}$ due to a changed surface dipole pointing to an impact of the wet feed on adsorbates, such as $\mathrm{OH}$ groups or adsorbed water.

An increased coverage with $\mathrm{OH}$ groups is supported by the difference in the $\mathrm{O}$ 1s core-level spectra of MoV-oxide in dry and wet gas feeds (Figure 6a). The spectra were fitted with two components $\mathrm{O}(1)$ and $\mathrm{O}(2)$ (at $1.2 \mathrm{eV}$ higher binding energy; for details, see Table S2). The high-binding-energy shoulder " $\mathrm{O}(2)$ " of the main peak increased in the steam-containing gas feed. The process is not completely reversible by switching back to dry feed (Figure S17).

The positive peak positions in the valence band difference spectrum $(\sim 6.1,8.65$, and $23.3 \mathrm{eV})$ (Figure $6 \mathrm{~b}$ ) are in good agreement with literature values for the surface hydroxylation of various metal oxides. ${ }^{45-50}$ Given the expected partial covalent bonding character and the contribution of metal $\mathrm{d}$ states to the high-binding-energy range of the valence band, ${ }^{11,36,51,52}$ and the contribution of oxygen $2 \mathrm{p}$ states to the metal states close to the Fermi level at $\sim 1.6 \mathrm{eV}$, an increased covalency could play a role in the observed changes in the valence band spectra. This may be related to the enrichment in $\mathrm{V}^{5+}$-oxide on the surface of $\mathrm{MoV}$ oxide in view of the increased covalency in vanadium oxides with a higher V oxidation state. ${ }^{52-54}$

It should be mentioned at this point that when interpreting the intensity increase in the valence band region and at the highbinding-energy side of the $\mathrm{O} 1 \mathrm{~s}$ core level in the steamcontaining feed as due to an increased surface hydroxylation, one has to be careful because of an overlap with other features. An unambiguous assignment of the shoulder $\mathrm{O}(2)$ of the $\mathrm{O}$ 1s peak is in many cases not possible because of overlapping contributions from "surface oxygen" species and adsorbed oxygen-containing carbon species, ${ }^{55-57}$ in addition to satellite lines from V $2 \mathrm{p}_{1 / 2}$ and V $2 \mathrm{p}_{3 / 2} .{ }^{52,53,58,59}$ In the present study, a C
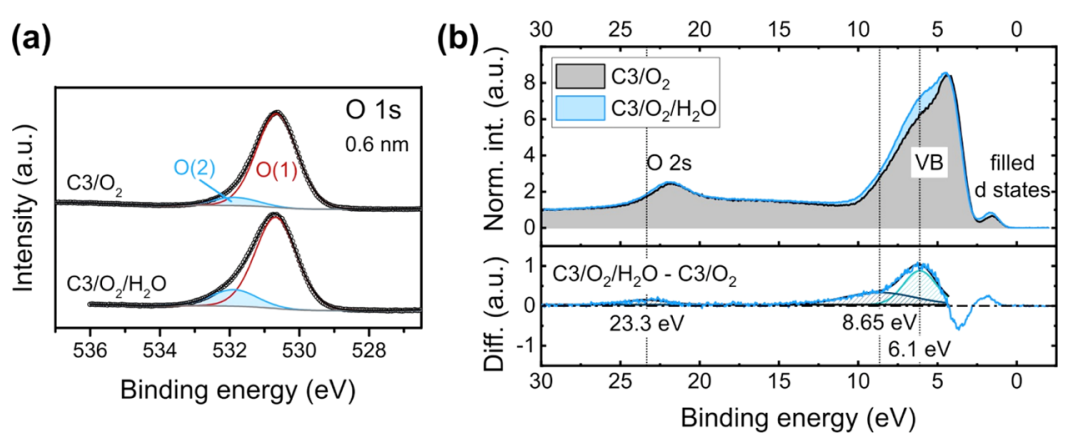

Figure 6. Changes in MoV-oxide $\mathrm{O} 1 \mathrm{~s}$ core level in dry and wet gas feeds fitted with two components $\mathrm{O}(1)$ and $\mathrm{O}(2), \lambda_{\mathrm{IMFP}}=0.6 \mathrm{~nm}$ (a), and valence band $(\mathrm{VB})$ spectra in dry and wet propane oxidation gas feeds normalized to the background at $30 \mathrm{eV}$ and difference $\operatorname{spectrum~Int}\left(\mathrm{C}_{3} \mathrm{H}_{8} / \mathrm{O}_{2} / \mathrm{H}_{2} \mathrm{O}\right)-$ $\operatorname{Int}\left(\mathrm{C}_{3} \mathrm{H}_{8} / \mathrm{O}_{2}\right)\left(270{ }^{\circ} \mathrm{C}, 25 \mathrm{~Pa}, E_{h v}\right.$ of $\left.100 \mathrm{eV}\right)(\mathrm{b})$. 
1s signal appeared in the wet propane oxidation feed (Figure 7). The binding energy maximum at $284.6 \mathrm{eV}$ suggests the presence
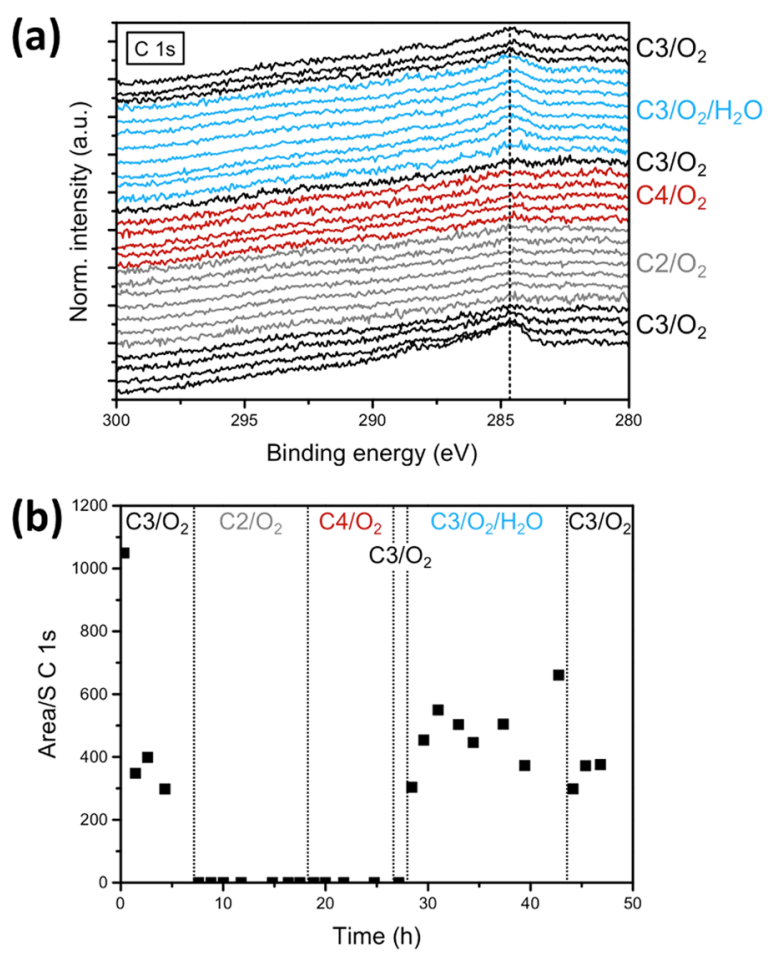

Figure 7. Evolution of surface carbon species on $\mathrm{MoV}$-oxide in different gas feeds $\left(25 \mathrm{~Pa}, 270{ }^{\circ} \mathrm{C}\right)$ : (a) C 1s core-level spectra and (b) quantitative analysis.

of adsorbed unsaturated, perhaps allylic, hydrocarbons. Oxygencontaining surface intermediates cannot be excluded due to the broad tail of the peak to higher binding energies. ${ }^{60}$ Adsorbed $\mathrm{H}_{2} \mathrm{O}$ is usually reported at larger chemical shifts (higher binding energies), ${ }^{55-57,61,62}$ which was not observed on MoV-oxide at a temperature of $270{ }^{\circ} \mathrm{C}$. The intensity increase in the $\mathrm{O} 2 \mathrm{~s}$ region of MoV-oxide at about $23.3 \mathrm{eV}$ should not overlap with satellites and is thus supporting the interpretation in terms of the increased coverage with hydroxyl groups. Hence, it is likely that the increase in intensity in the steam-containing propane oxidation gas feed in the valence band region between $\sim 5$ and 14 $\mathrm{eV}$, in the $\mathrm{O} 2 \mathrm{~s}$ region at $\sim 23.3 \mathrm{eV}$, and at the high-bindingenergy side of the $\mathrm{O} 1 \mathrm{~s}$ core-level peak at $\sim 531.8 \mathrm{eV}$ is due to the formation of or increasing coverage with $\mathrm{OH}$ groups on the MoV-oxide surface.

In summary, the addition of steam to the propane oxidation feed has the following effects on MoV-oxide:

1. The conductivity of MoV-oxide decreases in the presence of steam.

2. The surface concentration of vanadium and the average surface oxidation state increase due to migration of $\mathrm{V}^{5+}$ out of the hexagonal channels of the framework to the surface accounting also for changes in the covalent character of the corresponding surface vanadyl bonds.

3. The work function decreases by $200 \mathrm{meV}$ with small changes in the valence band onset and the core-level positions $\left(\Delta E_{\text {bind }}<70 \mathrm{meV}\right)$ suggesting a change in band bending $\left(e \Delta V_{\mathrm{s}}\right)$. However, the change of the surface dipole due to modifications in the surface termination, including surface hydroxylation, prevails.
4. Surface hydroxylation is supported by changes in the $\mathrm{O} 1 \mathrm{~s}$, $\mathrm{O} 2 \mathrm{~s}$, and valence band spectra.

\section{DISCUSSION}

On the Origin of the Conductivity and Permittivity Response. The data clearly show that the electrical conductivity of $\mathrm{MoV}$-oxide, determined with an operando MCPT method, responded sensitively to changes in the gas phase, even to the small changes associated with different contact times and hence reactant conversion and product selectivity. It may be assumed that there is no simple relation between, e.g., the conductivity and the partial pressure of oxygen, which is frequently observed for semiconducting metal oxide gas sensors. The conductivity is rather a function of the chemical potential of the surrounding atmosphere, which affects the surface overlayer on $\mathrm{MoV}$-oxide and surface oxidation states. Hence, the charge carrier density (or the degree of reduction) is influenced by (i) the alkane chain length, (ii) the reactant conversion with an increased catalyst reduction at higher conversions, and (iii) the selectivity to the different reaction products. The product distribution depends both on the reaction, i.e., it is different for the oxidation of ethane, propane (dry/wet), and $n$-butane, and on the reactant conversion, where an increased formation of the undesired oxidation products acetic acid, $\mathrm{CO}$, and $\mathrm{CO}_{2}$ occurs at higher conversions. A reasonable explanation for the largest conductivity changes in the dry propane oxidation feed is the associated largest change in the product distribution and hence in the number of charge carriers transferred at different contact times (Figure 1). Not only is the higher propane conversion itself related to an increased reduction of the catalyst, but also the decrease of the selectivity to propene and the increased formation of $\mathrm{CO}$ and $\mathrm{CO}_{2}$ (and of the acids) (eqs 4-6), as well as the associated increased oxygen conversion. This is suggested to be the reason for the conductivity decrease of the p-type semiconductor MoVoxide at higher reactant conversions and enhanced carbon oxide formation.

$$
\begin{aligned}
& \mathrm{C}_{3} \mathrm{H}_{8}+1 / 2 \mathrm{O}_{2} \rightarrow \mathrm{C}_{3} \mathrm{H}_{6}+\mathrm{H}_{2} \mathrm{O} \quad\left(2 e^{-} \text {transferred }\right) \\
& \mathrm{C}_{3} \mathrm{H}_{8}+7 / 2 \mathrm{O}_{2} \rightarrow 3 \mathrm{CO}+4 \mathrm{H}_{2} \mathrm{O} \quad\left(14 e^{-} \text {transferred }\right) \\
& \mathrm{C}_{3} \mathrm{H}_{8}+5 \mathrm{O}_{2} \rightarrow 3 \mathrm{CO}_{2}+4 \mathrm{H}_{2} \mathrm{O} \quad\left(20 e^{-} \text {transferred }\right)
\end{aligned}
$$

In the oxidation of ethane over MoV-oxide, the main product was ethene even at high conversions. The rather flat $S-X$ curve can likewise serve as explanation for the small conductivity changes at different contact times in this gas feed.

Concerning the origin of the changes of the permittivity $(\tilde{\varepsilon}=$ $\left.\varepsilon^{\prime}-\mathrm{i} \varepsilon^{\prime \prime}\right)$ or electrical conductivity $(\sigma)$ in $\mathrm{MoV}$-oxide, changes in the conductivity are likely caused by a change in the number of charge carriers $n$ or in their mobility $\mu$, i.e., $\Delta \sigma=e(\mu \Delta n+n \Delta \mu)$, where $e$ denotes the elementary charge. It is assumed that the charge carrier concentration usually plays a major role in the conductivity change $(\Delta \sigma \propto \Delta n) .{ }^{63}$ The first and kinetically relevant step in the oxidation of propane, the abstraction of a hydrogen atom, for instance, may be associated with a consumption of holes (subscript " $h$ ") explaining the observed conductivity decrease at higher conversions. The conductivity is related to the imaginary part of the permittivity $\varepsilon^{\prime \prime}$ (cf. eq 1 ), which represents the energy loss. ${ }^{13}$ A significant contribution of 
ionic conductivity to $\varepsilon^{\prime \prime}$ in the microwave frequency range is unlikely to occur because of the higher mass of ions compared to electrons or holes. ${ }^{31}$ Changes in the charge carrier concentration can also occur in the surface or subsurface region. In the case of a space-charge-layer-modified conductivity response, e.g., due to changes in the surface termination layer, the charge carrier density in the subsurface space charge region is affected. The conductivity as a function of the coordinate $x$ pointing away from the surface (at $x=0$ ) into the bulk then changes according to eq 7, where $e V(x)$ denotes the band bending at position $x$, with $k$ and $T$ being the Boltzmann constant and temperature, respectively. ${ }^{64}$

$$
\sigma(x) \approx e \mu_{\mathrm{h}} n_{\mathrm{h}}(x)=e \mu_{\mathrm{h}} n_{\mathrm{h}}(\text { bulk }) \exp \left(-\frac{e V(x)}{k T}\right)
$$

When it comes to the methodology, i.e., to the microwave cavity perturbation measurements, care must be taken when interpreting the response of $\varepsilon^{\prime}$. In the vicinity of the depolarization peak, which is observed for higher conductivities and large conductivity changes, the MCPT frequency shift would be related to both $\varepsilon^{\prime}$ and $\varepsilon^{\prime \prime}$ as well as to geometric factors of the sample, ${ }^{65}$ and considerable changes of the frequency shift are expected. ${ }^{66}$ It should be kept in mind that the interpretations are made under the assumption that the change of the frequency shift is dominated by the response of $\varepsilon^{\prime}$ of the sample. The real part of the permittivity $\varepsilon^{\prime}$ describes the energy storage. ${ }^{13}$ The contribution of surface dipoles is generally recognized as being an important factor for the response of $\varepsilon^{\prime}$ in transition-metal oxides. ${ }^{13,67-69}$ Additionally, defects as polarization sources, for instance, oxygen vacancies, ${ }^{70,71}$ and their influence on $\varepsilon^{\prime}$ have frequently been discussed. ${ }^{13,67,68,72}$ Another contribution to $\varepsilon^{\prime}$ may arise from dielectric relaxation via a dipole reorientation by "discrete jumps" associated with mixed-valent metal ions. ${ }^{70,73,74}$ In a similar way, one could think of a contribution of $\mathrm{V}^{4+} / \mathrm{V}^{5+}$ pairs in MoV-oxide to the dielectric relaxation $\left(V^{4+}+h^{+} \leftrightarrows V^{5+}\right)$, also to the energy storage. Such a hopping process of course also contributes to the loss and hence to $\varepsilon^{\prime \prime}$. It is assumed that the most important mechanisms leading to changes in $\varepsilon^{\prime}$ in $\mathrm{MoV}$ oxide, e.g., between the dry and wet propane oxidation gas feed or with increasing reactant conversion are reaction- or adsorption-induced changes in the surface dipole (changes in the surface termination layer, surface oxidation states, coverage with different adsorbates, or $\mathrm{OH}$ groups) or in the number of $\mathrm{V}^{4+} / \mathrm{V}^{5+}$ centers. It should be stressed that a decrease of $\varepsilon^{\prime}$ of MoV-oxide was observed (Figure S3), e.g., at higher reactant conversions, which renders the interpretation in terms of less defects unlikely, but a decrease of the surface dipole might still occur. Since the changes in $\varepsilon^{\prime}$ and in $\varepsilon^{\prime \prime}$ were always found to be in the same direction, it is concluded that they are correlated and have a common origin in MoV-oxide.

Comparison of MoV-Based Oxide Catalysts. In this section, differences in the electronic structure and the semiconducting properties of MoV-oxide and MoVTeNboxide will be discussed in view of their opposite conductivity response, which may be explained by a p-type behavior of the former and an n-type behavior of the latter. Besides MoVTeNboxide (M1 phase), ${ }^{10}$ also MoVTeNb-oxide (M2 phase) ${ }^{75}$ and MoVSbNb-oxide (M1 phase) ${ }^{76}$ were found to exhibit n-type conduction behavior. This indicates that the additional elements, $\mathrm{Te}$ or $\mathrm{Sb}$ and $\mathrm{Nb}$, have an impact on the electronic structure.
First of all, there are differences in the chemical composition of these mixed-metal oxides. In the orthorhombic M1 structure (ICSD 55097) $)^{1,2}$ of MoVTeNb-oxide, $\mathrm{Nb}^{5+}$ substitutes molybdenum in the pentagonal bipyramids (M9 position), and $\mathrm{Te}^{4+}\left(\mathrm{Te}^{6+}\right)$ partly occupies the hexagonal channels (M12 position) under the formation of tellurium oxide chains. ${ }^{1-3,77}$ In these hexagonal channels, extra-framework vanadium was observed in MoV-oxide. ${ }^{12}$ In the distorted octahedral linker positions (M1, M3, M4, M7 sites), a mixed Mo and V occupancy was found, while the other "octahedral" sites (M2, M5, M6, M8, M10, M11) are occupied by Mo in both $\mathrm{MoVTeNbO}_{\mathrm{x}}$ and $\mathrm{MoVO}_{\mathrm{x}}{ }^{1-3,12,78}$

At first glance, no major differences are observed between the p-type MoV-oxide (M1) and the n-type MoVTeNb-oxide (M1) ${ }^{11}$ regarding their valence band spectra. Still, the conduction band structure, for instance, might be different to some extent. The n-type semiconducting behavior of many transition-metal oxides is believed to be caused by an oxygendeficit (nonstoichiometry) and the related formation of shallow donor levels close to the conduction band minimum. ${ }^{79-84}$ Conversely, the opposite factors should be favorable for p-type metal oxide semiconductors, in particular the formation of shallow acceptor levels close to the valence band onset ${ }^{81,84}$ and a low ionization potential of the semiconductor. ${ }^{82,84}$ P-type behavior is frequently observed for oxides where there exists a stable higher oxidation state of the metal ion or a (partially) filled $\mathrm{d}$ shell, which lies close to the $\mathrm{O} 2 \mathrm{p}$ energy, ${ }^{79-81,84}$ for instance, $\mathrm{V}^{4+}$ in MoV-oxide, which can be readily oxidized to $\mathrm{V}^{5+}$. Vanadium is considered here as an important element because it is the main redox-active cation in these catalysts. Both $\mathrm{MoVTeNb}$-oxide and $\mathrm{MoV}$-oxide have a mixed vanadium oxidation state; however, in $\mathrm{MoV}$-oxide, $\mathrm{V}^{4+}$ is the main surface (or near-surface) vanadium species (oxidation state $<4.5$ like in the p-type vanadyl pyrophosphate VPP catalyst, ${ }^{31,37,42}$ but not $>4.5$ like in MoVTeNb-oxide ${ }^{10}$ ). The formation of $\mathrm{V}^{5+}$ in $\mathrm{MoV}$ oxide could be related to the creation of acceptor states leading to the p-type behavior by introducing holes in the valence band upon thermal emission, in line with the suggestions for vanadyl pyrophosphate. $^{31,85}$ Structurally, this may be caused by the formation of cation vacancies during thermal treatment ${ }^{12}$ that causes occupation of metal positions in the hexagonal channels by $\mathrm{V}^{5+}$ in agreement with the high abundance of defects in MoVoxide. $^{32}$ In MoVTeNb-oxide, on the other hand, vanadium occurs mainly in its highest oxidation state $5+$ at the surface (V oxidation state $>4.5) .{ }^{10}$ This may be compared to the n-type $\mathrm{V}_{2} \mathrm{O}_{5}$ ( or $\mathrm{V}_{2} \mathrm{O}_{5-x}$ ), where defect levels introduced by the nonstoichiometry and the related $\mathrm{V}^{4+}$ formation can form donor levels close to the conduction band. ${ }^{86}$ Other $\mathrm{V}^{5+}$ compounds like the different vanadyl phosphates $\mathrm{VOPO}_{4}$ are likewise n-type semiconductors. ${ }^{87}$ Similarly, $\mathrm{MoO}_{3}$ exhibits n-type behavior due to oxygen vacancies associated with partially occupied Mo $4 \mathrm{~d}$ states (nonstoichiometric $\mathrm{MoO}_{3-x}$ ). ${ }^{88-91}$ For both binary oxides, a polaron conduction mechanism was suggested. ${ }^{92-96}$ An activated mobility is also likely to occur in MoV-oxide, which was shown by the apparent activation energy of conduction. Furthermore, the partial covalent bonding character in MoVoxide should be favorable for the charge carrier mobility in view of the smaller effective mass of the charge carriers upon an enhancement of the covalency. ${ }^{80-83,97}$

Regarding the overall surface composition, the vanadium content is higher in MoV-oxide ( $24 \% \mathrm{~V} ; \mathrm{V} /$ Mo ratio of 0.32$)$ than in MoVTeNb-oxide $\left(\sim 15 \% \mathrm{~V} ; \mathrm{V} / \mathrm{Mo}\right.$ ratio of $\left.0.27^{10}\right)$, which could be related to the lower selectivity of MoV-oxide. In 
particular, an accumulation of vanadium in its highest oxidation state $5+$ might enhance combustion reactions. A comparison of the $\mathrm{V}^{5+}$ surface content of the catalysts shows however a slightly lower amount of $\mathrm{V}^{5+}$ on MoV-oxide $\left(\sim 7.9 \% \mathrm{~V}^{5+}\right.$ on $\mathrm{MoVO}_{\mathrm{x}}$ compared to $\sim 8.7 \% \mathrm{~V}^{5+}$ on $\mathrm{MoVTeNbO}_{\mathrm{x}}{ }^{10}$ ) due to the lower average surface vanadium oxidation state. Both oxides show a (slight) decrease in the average vanadium oxidation state with increasing alkane chain length from ethane to $n$-butane, ${ }^{10}$ which is in line with the increased number of electrons transferred in the oxidation of longer-chain alkanes.

Tellurium was suggested to be an essential component of the selective MoVTeNb-oxide catalyst taking part in the alkane activation $^{98}$ or in consecutive steps of the reaction. ${ }^{3,99}$ Furthermore, surface Te species may be important for achieving an efficient site isolation and may hence be crucial for the selectivity of the multicomponent catalyst. ${ }^{6,7,12}$ The absence of these Te-related factors can contribute to the lower selectivity of $\mathrm{MoV}$-oxide in propane and $n$-butane oxidation compared to $\mathrm{MoVTeNb}$-oxide because these reactions proceed via less stable, for example, allylic intermediates. In addition, the occupation of the hexagonal channels by either vanadium or tellurium can have implications for their respective electronic properties. Besides the application of tellurium compounds in heterogeneous catalysis, tellurides are frequently used in electronic applications (e.g., solar cells, thermoelectric materials, and optical storage media). ${ }^{100,101}$ There are reports of n-type semiconducting mixed-metal tellurium oxides ${ }^{102}$ and of Te-doped n-type $\operatorname{In}_{2} \mathrm{O}_{3}$, which leads to an altered conduction band structure but with a poor doping effectiveness. ${ }^{103}$ Tellurium doping was also applied to enhance the p-type conductivity ${ }^{104}$ of other metal oxides when substituting oxygen, e.g., in $\mathrm{CuAlO}_{2}$, where it leads to a decrease of the band gap and increased covalency. ${ }^{105,106}$ Recently, it has been proposed that the reduction and subsequent emission of tellurium from the hexagonal channels in the M1 structure in the course of the oxidation reaction create reactive $\mathrm{O}^{-}$species, which are involved in the alkane activation ( similar to vanadyl species $\left.\mathrm{V}^{5+}=\mathrm{O} \rightarrow \mathrm{V}^{4+}-\mathrm{O}^{-}\right) .{ }^{107}$ Importantly, the authors indicated that the removal of Te might ultimately change the semiconducting properties from n-type (with $\mathrm{Te}$ ) to p-type (without Te) based on density functional theory (DFT) calculations. $^{107}$ The present study can be taken as first experimental evidence, which verifies the opposite semiconducting properties of M1 catalysts with and without tellurium. While the localization of a hole creating an electrophilic $\mathrm{O}^{-}$species may contribute to the reactivity of the catalyst, the p-type conductivity of MoV-oxide does not seem to be favorable for the catalytic performance, in particular for the selectivity in propane and $n$-butane oxidation. Yet, other factors as mentioned above (e.g., the violation of site isolation through connected $\mathrm{V}_{\mathrm{x}} \mathrm{O}_{\mathrm{y}}$ surface patches) may contribute to the lower selectivity. Theoretical studies aiming at explaining differences in the semiconducting behavior of MoV-based oxides at a fundamental level are highly desirable to better understand these complex catalysts.

The different semiconducting properties of $\mathrm{MoV}$-oxide compared to MoVTeNb-oxide can have implications for their respective catalytic properties, for instance, regarding the oxygen activation or alkane activation. It is thought that the oxygen activation is facilitated on n-type transition-metal oxide catalysts, i.e., it is favored by a high-lying Fermi level, while the $\mathrm{C}-\mathrm{H}$ activation might require a low-lying Fermi level. ${ }^{108}$ Generally, the availability of free electrons or holes will be different, which may influence their catalytic properties. In this context, it is interesting to note that the catalytic performance of $\mathrm{MoV}$-oxide in the dry and wet propane oxidation is more similar to the one of vanadyl pyrophosphate ${ }^{42}$ than to MoVTeNb-oxide, with the latter showing a higher selectivity toward propene in the dry propane oxidation feed and a higher selectivity to acrylic acid in the wet feed. ${ }^{8}$

As was discussed above (with the MCPT being taken as highly sensitive integral method), the opposite conductivity response of MoV-oxide and MoVTeNb-oxide to different alkane oxidation gas feeds could originate from changes in the surface-subsurface region or in the bulk conductivity. In the case of a gas-phase-induced change of the surface charge or surface termination layer, it is likely that a change in band bending will occur shifting the relative positions of the valence band and conduction band onset and of surface states with respect to the Fermi level. This would affect the electron distribution (occupation of valence band, conduction band, and surface states) and the barrier height for bulk-surface charge transfer. In the NAP-XPS experiments, a change in band bending would manifest itself in an energy shift of the entire photoelectron spectrum, i.e., in a consistent shift of the valence band and core-level binding energies as well as of the work function. ${ }^{109}$ The present experiments revealed another important difference between MoV-oxide and MoVTeNboxide. The negligible effect of the alkane chain length on the work function or valence band onset of MoV-oxide leads to the conclusion that no change in band bending occurred between the different dry alkane oxidation gas feeds. This is in contrast to MoVTeNb-oxide, where energy shifts of $0.09-0.2 \mathrm{eV}$ for the work function and of up to $0.08 \mathrm{eV}$ for the valence band onset and core-level binding energies were reported between ethane and $n$-butane oxidation feeds. ${ }^{10}$ The linear correlation between conductivity and work function observed in the case of MoVTeNb-oxide strongly supported the interpretation of a space-charge-layer-modified conductivity response. ${ }^{10}$ On the other hand, there is no correlation between work function changes and electrical conductivity changes in $\mathrm{MoV}$-oxide (Figure 3c). This result further strengthens the hypothesis that selective catalysts like MoVTeNb-oxide or vanadyl pyrophosphate exhibit a dynamic gas-phase-dependent surface potential barrier, which is thought to control the charge transfer between the catalyst bulk and the adsorbed reactants. ${ }^{37}$ The idea is that this dynamic barrier limits the bulk-surface electron transfer and hence the availability of highly reactive oxygen species that favor combustion reactions. ${ }^{37}$ The behavior of $\mathrm{MoV}$-oxide is similar to that of the unselective $\mathrm{V}_{2} \mathrm{O}_{5}$, which also showed only small effects of the gas phase on the electronic structure. ${ }^{37}$ The missing "control function" for charge transfer via a band bending (surface potential barrier) that sensitively adapts to the chemical potential of the surrounding atmosphere may be linked to the rather low selectivity of $\mathrm{MoV}$-oxide in the oxidation of propane or $n$-butane. It should be noted that multiple parameters influence the selectivity, including the complexity of the reaction network and perhaps an involvement of the main group element tellurium. The sensitive response of the electrical conductivity to the catalytic reaction at the surface as seen in the contact time variation experiments (Figures 1 and S14) is taken as evidence for the relevance of the obtained data for the catalytic performance.

The Influence of Steam. The permittivity response of MoV-oxide in the dry/wet propane oxidation cycles can be understood in terms of water chemisorption and changes of the catalyst surface such as changes in the oxidation states and the 
surface composition, including surface hydroxylation. Furthermore, steam causes a different product distribution (different selectivity), i.e., a different chemical potential in the gas phase, which will probably affect the conductivity of $\mathrm{MoV}$-oxide as well. Neither dielectric relaxation from mobile multilayers of water nor proton conduction are likely to play a role in MoV-oxide, first of all because a decrease of the conductivity and of $\varepsilon^{\prime}$ was observed in a wet propane oxidation feed. In addition, a higher real part of the permittivity would only be expected for more or less mobile physisorbed multilayers of water ${ }^{110}$ that can reorient with the microwave field and a significant contribution of proton conductivity was only observed on metal oxides at room temperature and below because of the desorption of water at higher temperatures. ${ }^{75,111-115}$

The additional chemical modification of the surface of MoVoxide, which was shown by NAP-XPS, complicates the interpretation of the conductivity response. The addition of steam leads to the formation of a surface termination layer enriched in $\mathrm{V}^{5+}$ and hence to a semiconductor- or insulatorsemiconductor heterostructure between the MoV-oxide (M1) bulk and this interface. An appearance of a shoulder in the valence band, like in the present study, was also observed for MoVTeNb-oxide (M1). ${ }^{11}$ The binding energy of this shoulder below $\sim 6 \mathrm{eV}$ agrees well with the formation of $\mathrm{OH}$ groups on the MoV-oxide surface, which is supported by an increase in the $\mathrm{O} 2 \mathrm{~s}$ emission and at the high-binding-energy side of the $\mathrm{O} 1 \mathrm{~s}$ core level. Hence, also an increased surface hydroxylation and modified acid-base properties may play a role in the formation of the active surface layer, as well as, for instance, for the modified surface polarity, which is suggested to be the reason for the decrease of the work function and the real part of the permittivity of MoV-oxide. An increased intensity of a peak in the valence band close to the Fermi level was observed, which might suggest contributions of oxygen $2 p$ states in this energy range and hence an increase in the covalent character of the corresponding $\mathrm{V}=\mathrm{O}$ bonds on the surface. The changes in the surface termination layer and in the occupation of the V $3 \mathrm{~d}$ level are likely to affect the electrical conductivity as well. In contrast to the irreversible changes in the core-level spectra, the work function changes were found to be reversible and the (V 3d/Mo $4 d$ ) peak area close to the Fermi level at least partly decreased by the subsequent treatment in a dry propane oxidation gas feed.

The conductivity or permittivity changes of MoV-oxide in the dry/wet cycles were found to be rather reversible, although a slight decrease of the conductivity (or $\varepsilon^{\prime \prime}$ ) with time on stream was observed. Since a decrease of the MCPT conductivity in a steam-containing propane oxidation feed was not only observed for MoV-oxide, but also for the n-type MoVTeNb-oxide (M1 phase $)^{11}$ and for the p-type vanadyl pyrophosphate, ${ }^{42}$ a change in the charge carrier density is unlikely to play a dominant role. Hence, the charge carrier mobility could be decreased. The changes in $\varepsilon^{\prime \prime}$ or in the conductivity of MoV-oxide were also observed in the reference experiment without propane in the gas feed. A hydrolysis of the $\mathrm{V}-\mathrm{O}$ bonds in the hexagonal channels of MoV-oxide (M12 position in the M1 phase) followed by the migration to the surface and the creation of a $\mathrm{V}^{5+}$-enriched termination layer might also occur in the $\mathrm{O}_{2} / \mathrm{H}_{2} \mathrm{O} / \mathrm{N}_{2}$ gas feed at $270{ }^{\circ} \mathrm{C}$. Likewise, also an increased hydroxyl coverage of the $\mathrm{MoV}$-oxide surface seems reasonable. Hence, it is not surprising that $\varepsilon^{\prime \prime}$ or the conductivity also show a response to the dry/wet cycles in the reference experiment. It is interesting that this is not the case for the real part of the permittivity, which only showed a response to the dry/wet cycles in the propane oxidation feed
(Figure 4c). This may suggest an impact of hydrocarbons or oxygenates on the interaction of steam with MoV-oxide.

The formation of this surface termination layer coincided with an increased selectivity of $\mathrm{MoV}$-oxide toward acrylic acid and a decreased formation of $\mathrm{CO}$ and $\mathrm{CO}_{2}$. Steam is likely to have multiple functions for the catalytic performance. It may facilitate the creation of an active and selective surface layer. ${ }^{8}$ A small change in the surface potential barrier was observed in the presence of steam, which may contribute to modified bulksurface charge-transfer properties and improved control concerning the concentration of highly reactive electrophilic oxygen species on the surface. Balanced abundance of these species enables the formation of acrylic acid and prevents overoxidation to carbon dioxide.

Taken together, the results of this study contribute to the idea of a redox catalyst ${ }^{9}$ consisting of a semiconducting bulk and a surface layer, which is able to facilitate a charge carrier exchange between the reactants alkane and molecular oxygen.

\section{CONCLUSIONS}

MoV-based oxides are promising catalysts for the selective oxidation of light alkanes such as the oxidative dehydrogenation of ethane. We have presented operando electrical conductivity investigations of MoV-oxide (orthorhombic M1 phase) under dry and wet alkane oxidation conditions, which were complemented by the characterization of the electronic structure and surface composition with NAP-XPS. Essential electronic and functional properties of the two isostructural $\mathrm{MoV}$ - and MoVTeNb-oxides are summarized in Table 1.

Table 1. Electronic and Functional Properties of the Catalysts $\mathrm{MoVO}_{\mathrm{x}}$ and $\mathrm{MoVTeNbO}_{\mathrm{x}}$ with $\mathrm{M1}$ Structure in Propane Oxidation

\begin{tabular}{llll} 
& & \multicolumn{1}{c}{$\mathrm{MoVO}_{\mathrm{x}}$} & \multicolumn{1}{c}{ MoVTeNbO $_{\mathrm{x}}$} \\
semiconducting properties & & $\mathrm{p}$ & $\mathrm{n}$ \\
selectivity $^{a}$ to & dry & $30 / 0$ & $60 / 20$ \\
propene/acrylic acid (\%) & wet & $20 / 15$ & $60 / 30$ \\
conductivity in steam & & decrease & decrease $^{b}$ \\
$\begin{array}{l}\text { gas-phase-dependent band } \\
\text { bending }\end{array}$ & dry & no & yes $^{b}$ \\
& wet & small & no effect on extent of band \\
change & bending \\
surface V oxidation state & dry & 4.3 & $4.6^{c}$ \\
& wet & 4.4 & $4.8^{c}$
\end{tabular}

${ }^{a}$ Measured at $5 \%$ propane conversion in the absence or presence of $20 \%$ steam in the feed. ${ }^{8,12}$ According to ref $11 .{ }^{c}$ According to refs 8 , $10,12$.

Table 1 shows that the catalysts differ both in the type of majority charge carrier and in the impact of the gas atmosphere on the electronic structure in terms of changes in band bending (i.e., changes in a surface potential barrier). This work has demonstrated that MoV-oxide behaves as a p-type semiconductor with a small activation energy of conduction. Unlike MoVTeNb-oxide, ${ }^{10}$ no change in band bending in MoV-oxide was observed depending on the alkane chain length. The lack of a dynamic (gas-phase-dependent) surface potential barrier may be related to an insufficient control of charge transfer to adsorbed reactants and hence control of oxygen activation corresponding to an extension of the "site isolation" ${ }^{116}$ principle. Consequently, this (insufficient) control in less selective oxidation catalysts may be related to their (inferior) catalytic performance in complex oxidation reactions that involve highly 
reactive intermediates, such as oxidation of propane and $n$ butane.

A higher selectivity in the oxidation of propane to acrylic acid is obtained by adding steam to the gas feed. The operando MCPT and NAP-XPS experiments suggest the formation of a surface termination layer differing from the bulk structure, which may include an increased covalent character of the corresponding $\mathrm{V}=\mathrm{O}$ bonds, induced by the treatment of $\mathrm{MoV}$-oxide in a steam-containing propane oxidation feed. This can be described by a semiconductor- or insulator-semiconductor heterostructure between the MoV-oxide bulk and this interface. The observed small change in the surface potential barrier could also contribute to the increased selectivity in wet feed compared to dry feed. Future work should focus on extending the investigated parameter space in terms of testing a broader range of gas feed compositions as well as more mixed-metal oxide catalysts.

Our findings imply that differences in the electronic properties between M1 catalysts beyond a local description should be considered as well when rationalizing differences in their catalytic properties. Nonlocal electronic properties, which can be monitored by the conductivity, in combination with information about the surface and subsurface electronic structure are relevant for gaining a deeper understanding of heterogeneous selective oxidation catalysts. The observed differences between the M1 catalysts may contribute to their respective selectivities in the oxidation of light alkanes such as propane or $n$-butane, which exhibit an intricate reaction network. These "electronic factors" seem to be less relevant in the oxidative dehydrogenation of ethane to the stable ethene, which proceeds with a high selectivity over both M1 catalysts.

\section{ASSOCIATED CONTENT}

\section{S Supporting Information}

The Supporting Information is available free of charge on the ACS Publications website at DOI: 10.1021/acs.jpcc.9b01273.

Ex situ sample characterization of MoV-oxide M1 by Xray diffraction (XRD); further experimental details and supporting MCPT measurements; and additional NAPXPS spectra and the XPS core-level fit parameters (PDF)

\section{AUTHOR INFORMATION}

\section{Corresponding Author}

*E-mail: trunschke@fhi-berlin.mpg.de.

\section{ORCID}

Annette Trunschke: 0000-0003-2869-0181

\section{Notes}

The authors declare no competing financial interest.

\section{ACKNOWLEDGMENTS}

This work was performed within the framework of the BasCat collaboration between BASF SE, TU Berlin, FHI, and the cluster of excellence "Unified Concepts in Catalysis" (UniCat www. unicat.tu-berlin.de). Dr. Johannes Noack is gratefully acknowledged for the synthesis of the MoV-oxide M1 sample with the assistance of Stephen Lohr. The authors thank Dr. Frank Girgsdies for conducting the XRD measurements, and Maike Hashagen for the surface area determination. Furthermore, the authors are grateful for the continual support of the HZB staff at the ISISS beam line of BESSY II.

\section{ABBREVIATIONS}

AcA, acetic acid; AA, acrylic acid; DFT, density functional theory; EDX, energy-dispersive X-ray spectroscopy; GC, gas chromatography; MA, maleic anhydride; MCPT, microwave cavity perturbation technique; NAP-XPS, near-ambient-pressure X-ray photoelectron spectroscopy; PTR-MS, protontransfer-reaction mass spectrometer; $S-X$, selectivity-conversion; TM mode, transverse magnetic mode; UPS, ultraviolet photoelectron spectroscopy; VB, valence band; VPP, vanadyl pyrophosphate; W/F, contact time weight/flow; XRD, X-ray diffraction

\section{REFERENCES}

(1) DeSanto, P.; Buttrey, D. J.; Grasselli, R. K.; Lugmair, C. G.; Volpe, A. F. J.; Toby, B. H.; Vogt, T. Structural Aspects of the M1 and M2 Phases in MoVNbTeO Propane Ammoxidation Catalysts. Z. Kristallogr. - Cryst. Mater. 2004, 219, 152-165.

(2) Li, X.; Buttrey, D. J.; Blom, D. A.; Vogt, T. Improvement of the Structural Model for the M1 Phase Mo-V-Nb-Te-O Propane (Amm)oxidation Catalyst. Top. Catal. 2011, 54, 614-626.

(3) Grasselli, R. K.; Buttrey, D. J.; DeSanto, P.; Burrington, J. D.; Lugmair, C. G.; Volpe, A. F.; Weingand, T. Active Centers in Mo-V$\mathrm{Nb}-\mathrm{Te}-\mathrm{O}_{\mathrm{x}}(\mathrm{Amm})$ oxidation Catalysts. Catal. Today 2004, 91-92, 251-258.

(4) Ueda, W.; Vitry, D.; Katou, T. Structural Organization of Catalytic Functions in Mo-Based Oxides for Propane Selective Oxidation. Catal. Today 2004, 96, 235-240.

(5) Vitry, D.; Morikawa, Y.; Dubois, J. L.; Ueda, W. Propane Selective Oxidation Over Monophasic Mo-V-Te-O Catalysts Prepared by Hydrothermal Synthesis. Top. Catal. 2003, 23, 47-53.

(6) Hävecker, M.; Wrabetz, S.; Kröhnert, J.; Csepei, L.-I.; Naumann d'Alnoncourt, R.; Kolen'ko, Y. V.; Girgsdies, F.; Schlögl, R.; Trunschke, A. Surface Chemistry of Phase-Pure M1 MoVTeNb Oxide during Operation in Selective Oxidation of Propane to Acrylic Acid. J. Catal. 2012, 285, 48-60.

(7) Schlögl, R. Active Sites for Propane Oxidation: Some Generic Considerations. Top. Catal. 2011, 54, 627-638.

(8) Naumann d'Alnoncourt, R.; Csepei, L.-I.; Hävecker, M.; Girgsdies, F.; Schuster, M. E.; Schlögl, R.; Trunschke, A. The Reaction Network in Propane Oxidation over Phase-Pure MoVTeNb M1 Oxide Catalysts. J. Catal. 2014, 311, 369-385.

(9) Schlögl, R. Selective Oxidation: From a Still Immature Technology to the Roots of Catalysis Science. Top. Catal. 2016, 59, $1461-1476$.

(10) Heine, C.; Hävecker, M.; Sanchez-Sanchez, M.; Trunschke, A.; Schlögl, R; Eichelbaum, M. Work Function, Band Bending, and Microwave Conductivity Studies on the Selective Alkane Oxidation Catalyst MoVTeNb Oxide (Orthorhombic M1 Phase) under Operation Conditions. J. Phys. Chem. C 2013, 117, 26988-26997.

(11) Heine, C.; Hävecker, M.; Trunschke, A.; Schlögl, R.; Eichelbaum, M. The Impact of Steam on the Electronic Structure of the Selective Propane Oxidation Catalyst MoVTeNb Oxide (Orthorhombic M1 Phase). Phys. Chem. Chem. Phys. 2015, 17, 8983-8993.

(12) Trunschke, A.; Noack, J.; Trojanov, S.; Girgsdies, F.; Lunkenbein, T.; Pfeifer, V.; Hävecker, M.; Kube, P.; Sprung, C.; Rosowski, F.; et al. The Impact of the Bulk Structure on Surface Dynamics of Complex Mo-V-based Oxide Catalysts. ACS Catal. 2017, 7, 3061-3071.

(13) Chen, L. F.; Ong, C. K.; Neo, C. P.; Varadan, V. V.; Varadan, V. K. Microwave Electronics: Measurement and Materials Characterization. John Wiley \& Sons, Ltd.: Chichester, West Sussex, U.K., 2004.

(14) Eichelbaum, M.; Stößer, R.; Karpov, A.; Dobner, C.-K.; Rosowski, F.; Trunschke, A.; Schlögl, R. The Microwave Cavity Perturbation Technique for Contact-Free and in Situ Electrical Conductivity Measurements in Catalysis and Materials Science. Phys. Chem. Chem. Phys. 2012, 14, 1302-1312. 
(15) Dressel, M.; Klein, O.; Donovan, S.; Grüner, G. Microwave Cavity Perturbation Technique: Part III: Applications. Int. J. Infrared Millimeter Waves 1993, 14, 2489-2517.

(16) Helberg, H. W.; Dressel, M. Investigations of Organic Conductors by the Schegolev Method. J. Phys. I France 1996, 6, 1683-1695.

(17) Slater, J. C. Microwave Electronics. Rev. Mod. Phys. 1946, 18, $441-512$.

(18) Klein, O.; Donovan, S.; Dressel, M.; Grüner, G. Microwave Cavity Perturbation Technique: Part I: Principles. Int. J. Infrared Millimeter Waves 1993, 14, 2423-2457.

(19) Kajfez, D. Q Factor Measurements Using MATLAB; Artech House: Norwood, MA, 2011.

(20) Wernbacher, A. M.; Eichelbaum, M.; Risse, T.; Cap, S.; Trunschke, A.; Schlögl, R. Operando Electrical Conductivity and Complex Permittivity Study on Vanadia Oxidation Catalysts. J. Phys. Chem. C 2019, 123, 8005-8017.

(21) Dube, D. C. Study of Landau-Lifshitz-Looyenga's Formula for Dielectric Correlation between Powder and Bulk. J. Phys. D: Appl. Phys. 1970, 3, 1648-1652.

(22) Landau, L. D.; Lifshitz, E. M. Electrodynamics of Continuous Media; Pergamon Press: Oxford, U.K., 1960; Vol. 8.

(23) Looyenga, H. Dielectric Constants of Heterogeneous Mixtures. Physica 1965, 31, 401-406.

(24) Jonscher, A. K. Dielectric Relaxation in Solids. J. Phys. D: Appl. Phys. 1999, 32, R57-R70.

(25) Tanuma, S.; Powell, C. J.; Penn, D. R. Calculations of Electron Inelastic Mean Free Paths II. Data for 27 Elements over the 50-2000 eV Range. Surf. Interface Anal. 1991, 17, 911-926.

(26) Tanuma, S.; Powell, C. J.; Penn, D. R. Calculation of Electron Inelastic Mean Free Paths (IMFPs) VII. Reliability of the TPP-2M IMFP Predictive Equation. Surf. Interface Anal. 2003, 35, 268-275.

(27) Powell, C. J.; Jablonski, A. NIST Electron Inelastic-Mean-Free-Path Database, version 1.2; National Institute of Standards and Technology: Gaithersburg, MD, 2010.

(28) Yeh, J. J. Atomic Calculation of Photoionization Cross-Sections and Asymmetry Parameters; Gordon \& Breach Science Publishers: Langhorne, PE, 1993.

(29) Yeh, J. J.; Lindau, I. Atomic Subshell Photoionization Cross Sections and Asymmetry Parameters: $1 \leq \mathrm{Z} \leq 103$. At. Data Nucl. Data Tables 1985, 32, 1-155.

(30) Naumann d'Alnoncourt, R.; Kolen'ko, Y. V.; Schlögl, R.; Trunschke, A. A New Way of Probing Reaction Networks: Analyzing Multidimensional Parameter Space. Comb. Chem. High Throughput Screening 2012, 15, 161-169.

(31) Eichelbaum, M.; Hävecker, M.; Heine, C.; Karpov, A.; Dobner, C.-K.; Rosowski, F.; Trunschke, A.; Schlögl, R. The Intimate Relationship between Bulk Electronic Conductivity and Selectivity in the Catalytic Oxidation of $n$-Butane. Angew. Chem., Int. Ed. 2012, 51, 6246-6250.

(32) Masliuk, L.; Heggen, M.; Noack, J.; Girgsdies, F.; Trunschke, A.; Hermann, K. E.; Willinger, M. G.; Schlögl, R.; Lunkenbein, T. Structural Complexity in Heterogeneous Catalysis: Cataloging Local Nanostructures. J. Phys. Chem. C 2017, 121, 24093-24103.

(33) Brox, B.; Olefjord, I. ESCA Studies of $\mathrm{MoO}_{2}$ and $\mathrm{MoO}_{3}$. Surf. Interface Anal. 1988, 13, 3-6.

(34) Cruz, T. G. S.; Gorenstein, A.; Landers, R.; Kleiman, G. G.; deCastro, S. C. Electrochromism in $\mathrm{MoO}_{\mathrm{x}}$ Films Characterized by Xray Electron Spectroscopy. J. Electron Spectrosc. Relat. Phenom. 1999, 101-103, 397-400.

(35) Heber, M.; Grünert, W. Application of Ultraviolet Photoelectron Spectroscopy in the Surface Characterization of Polycrystalline Oxide Catalysts. 2. Depth Variation of the Reduction Degree in the Surface Region of Partially Reduced $\mathrm{V}_{2} \mathrm{O}_{5}$. J. Phys. Chem. B 2000, 104, 52885297.

(36) Wu, Q.-H.; Thissen, A.; Jaegermann, W.; Schüz, M.; Schmidt, P. C. Resonant Photoemission Spectroscopy Study of Electronic Structure of $\mathrm{V}_{2} \mathrm{O}_{5}$. Chem. Phys. Lett. 2006, 430, 309-313.
(37) Eichelbaum, M.; Hävecker, M.; Heine, C.; Wernbacher, A. M.; Rosowski, F.; Trunschke, A.; Schlögl, R. The Electronic Factor in Alkane Oxidation Catalysis. Angew. Chem., Int. Ed. 2015, 54, 29222926.

(38) Sanfiz, A. C.; Hansen, T. W.; Teschner, D.; Schnörch, P.; Girgsdies, F.; Trunschke, A.; Schlögl, R.; Looi, M. H.; Hamid, S. B. A. Dynamics of the MoVTeNb Oxide M1 Phase in Propane Oxidation. J. Phys. Chem. C 2010, 114, 1912-1921.

(39) Scanlon, D. O.; Watson, G. W.; Payne, D. J.; Atkinson, G. R.; Egdell, R. G.; Law, D. S. L. Theoretical and Experimental Study of the Electronic Structures of $\mathrm{MoO}_{3}$ and $\mathrm{MoO}_{2}$. J. Phys. Chem. C 2010, 114, $4636-4645$

(40) Tokarz-Sobieraj, R.; Hermann, K.; Witko, M.; Blume, A.; Mestl, G.; Schlögl, R. Properties of Oxygen Sites at the $\mathrm{MoO}_{3}(010)$ Surface: Density Functional Theory Cluster Studies and Photoemission Experiments. Surf. Sci. 2001, 489, 107-125.

(41) Werfel, F.; Minni, E. Photoemission Study of the Electronic Structure of Mo and Mo Oxides. J. Phys. C: Solid State Phys. 1983, 16, $6091-6100$

(42) Heenemann, M.; Heine, C.; Hävecker, M.; Trunschke, A.; Schlögl, R. Influence of Steam on a Vanadyl Pyrophosphate Catalyst During Propane Oxidation. J. Phys. Chem. B 2018, 122, 695-704.

(43) Kröger, M.; Hamwi, S.; Meyer, J.; Riedl, T.; Kowalsky, W.; Kahn, A. Role of the Deep-Lying Electronic States of $\mathrm{MoO}_{3}$ in the Enhancement of Hole-Injection in Organic Thin Films. Appl. Phys. Lett. 2009, 95, No. 123301.

(44) Seitz, H.; Juan, A.; Brizuela, G.; Irigoyen, B. The Effect of MetalCation Vacancies on Vanadium Antimonate Surface Properties. A Theoretical Study. J. Phys. Chem. C 2013, 117, 20548-20556.

(45) Kurtz, R. L.; Henrich, V. E. Surface Electronic Structure and Chemisorption on Corundum Transition-Metal Oxides: $\mathrm{V}_{2} \mathrm{O}_{3}$. Phys. Rev. B 1983, 28, 6699-6706.

(46) Flavell, W. R.; Thomas, A. G.; Hollingworth, J.; Warren, S.; Grice, S. C.; Dunwoody, P. M.; Mitchell, C. E. J.; Marr, P. G. D.; Teehan, D.; Downes, S.; et al. Electronic Structure and Surface Reactivity of $\mathrm{La}_{1-\mathrm{x}} \mathrm{Sr}_{\mathrm{x}} \mathrm{CoO}_{3}$. Faraday Discuss. 1999, 114, 407-420.

(47) Ranke, W. Low Temperature Adsorption and Condensation of $\mathrm{O}_{2}, \mathrm{H}_{2} \mathrm{O}$ and $\mathrm{NO}$ on $\mathrm{Pt}(111)$, Studied by Core Level and Valence Band Photoemission. Surf. Sci. 1989, 209, 57-76.

(48) Ranke, W.; Kuhr, H. J. Oxygen 2s Spectroscopy. Phys. Rev. B 1989, 39, 1595-1601.

(49) Ranke, W.; Xing, Y. R. Orientation Dependent Adsorption on a Cylindrical Silicon Crystal: I. Water. Surf. Sci. 1985, 157, 339-352.

(50) Warren, S.; Flavell, W. R.; Thomas, A. G.; Hollingworth, J.; Dunwoody, P. M.; Downes, S.; Chen, C. Adsorption of $\mathrm{H}_{2} \mathrm{O}$ on Single Crystal CuO. Surf. Sci. 1999, 436, 1-8.

(51) Khyzhun, O. Y.; Strunskus, T.; Grünert, W.; Wöll, C. Valence Band Electronic Structure of $\mathrm{V}_{2} \mathrm{O}_{5}$ as Determined by Resonant Soft Xray Emission Spectroscopy. J. Electron Spectrosc. Relat. Phenom. 2005, $149,45-50$

(52) Zimmermann, R.; Claessen, R.; Reinert, F.; Steiner, P.; Hüfner, S. Strong Hybridization in Vanadium Oxides: Evidence from Photoemission and Absorption Spectroscopy. J. Phys.: Condens. Matter 1998, 10, 5697-5716.

(53) Bocquet, A. E.; Mizokawa, T.; Morikawa, K.; Fujimori, A.; Barman, S. R.; Maiti, K.; Sarma, D. D.; Tokura, Y.; Onoda, M. Electronic Structure of Early 3d-Transition-Metal Oxides by Analysis of the 2p Core-Level Photoemission Spectra. Phys. Rev. B 1996, 53, 11611170 .

(54) Sawatzky, G. A.; Post, D. X-ray Photoelectron and Auger Spectroscopy Study of Some Vanadium Oxides. Phys. Rev. B 1979, 20, $1546-1555$

(55) Ketteler, G.; Yamamoto, S.; Bluhm, H.; Andersson, K.; Starr, D. E.; Ogletree, D. F.; Ogasawara, H.; Nilsson, A.; Salmeron, M. The Nature of Water Nucleation Sites on $\mathrm{TiO}_{2}(110)$ Surfaces Revealed by Ambient Pressure X-ray Photoelectron Spectroscopy. J. Phys. Chem. C 2007, 111, 8278-8282.

(56) Stoerzinger, K. A.; Hong, W. T.; Azimi, G.; Giordano, L.; Lee, Y.L.; Crumlin, E. J.; Biegalski, M. D.; Bluhm, H.; Varanasi, K. K.; Shao- 
Horn, Y. Reactivity of Perovskites with Water: Role of Hydroxylation in Wetting and Implications for Oxygen Electrocatalysis. J. Phys. Chem. C 2015, 119, 18504-18512.

(57) Yamamoto, S.; Kendelewicz, T.; Newberg, J. T.; Ketteler, G.; Starr, D. E.; Mysak, E. R.; Andersson, K. J.; Ogasawara, H.; Bluhm, H.; Salmeron, M.; et al. Water Adsorption on $\alpha-\mathrm{Fe}_{2} \mathrm{O}_{3}(0001)$ at Near Ambient Conditions. J. Phys. Chem. C 2010, 114, 2256-2266.

(58) Mossanek, R. J. O.; Mocellin, A.; Abbate, M.; Searle, B. G.; Fonseca, P. T.; Morikawa, E. Cluster Model and Band Structure Calculations of $\mathrm{V}_{2} \mathrm{O}_{5}$ : Reduced $\mathrm{V}^{5+}$ Symmetry and Many-Body Effects. Phys. Rev. B 2008, 77, No. 075118.

(59) Silversmit, G.; Depla, D.; Poelman, H.; Marin, G. B.; De Gryse, R. Determination of the V2p XPS Binding Energies for Different Vanadium Oxidation States $\left(\mathrm{V}^{5+}\right.$ to $\left.\mathrm{V}^{0+}\right)$. J. Electron Spectrosc. Relat. Phenom. 2004, 135, 167-175.

(60) Reitz, J. B.; Solomon, E. I. Propylene Oxidation on Copper Oxide Surfaces: Electronic and Geometric Contributions to Reactivity and Selectivity. J. Am. Chem. Soc. 1998, 120, 11467-11478.

(61) Biesinger, M. C.; Payne, B. P.; Grosvenor, A. P.; Lau, L. W. M.; Gerson, A. R.; Smart, R. S. C. Resolving Surface Chemical States in XPS Analysis of First Row Transition Metals, Oxides and Hydroxides: Cr, $\mathrm{Mn}, \mathrm{Fe}, \mathrm{Co}$ and Ni. Appl. Surf. Sci. 2011, 257, 2717-2730.

(62) Kendelewicz, T.; Kaya, S.; Newberg, J. T.; Bluhm, H.; Mulakaluri, N.; Moritz, W.; Scheffler, M.; Nilsson, A.; Pentcheva, R.; Brown, G. E. $\mathrm{X}$-ray Photoemission and Density Functional Theory Study of the Interaction of Water Vapor with the $\mathrm{Fe}_{3} \mathrm{O}_{4}(001)$ Surface at NearAmbient Conditions. J. Phys. Chem. C 2013, 117, 2719-2733.

(63) Eichelbaum, M.; Glaum, R.; Hävecker, M.; Wittich, K.; Heine, C.; Schwarz, H.; Dobner, C.-K.; Welker-Nieuwoudt, C.; Trunschke, A.; Schlögl, R. Towards Physical Descriptors of Active and Selective Catalysts for the Oxidation of $n$-Butane to Maleic Anhydride. Chem CatChem 2013, 5, 2318-2329.

(64) Lüth, H. Solid Surfaces, Interfaces and Thin Films; 5 ed.; SpringerVerlag: Berlin, 2010.

(65) Bauhofer, W. Determination of Semiconductor Energy Gaps Using the Microwave Cavity Perturbation Method. J. Phys. E: Sci. Instrum. 1981, 14, 934-938.

(66) Ong, N. P. Microwave Cavity-Perturbation Equations in the Skin-Depth Regime. J. Appl. Phys. 1977, 48, 2935-2940.

(67) Chen, Y.-J.; Zhang, F.; Zhao, G.-g.; Fang, X.-y.; Jin, H.-B.; Gao, P.; Zhu, C.-L.; Cao, M.-S.; Xiao, G. Synthesis, Multi-Nonlinear Dielectric Resonance, and Excellent Electromagnetic Absorption Characteristics of $\mathrm{Fe}_{3} \mathrm{O}_{4} / \mathrm{ZnO}$ Core/Shell Nanorods. J. Phys. Chem. C 2010, 114, 9239-9244.

(68) Du, Y.; Liu, W.; Qiang, R.; Wang, Y.; Han, X.; Ma, J.; Xu, P. Shell Thickness-Dependent Microwave Absorption of Core-Shell $\mathrm{Fe}_{3} \mathrm{O}_{4} @$ C Composites. ACS Appl. Mater. Interfaces 2014, 6, 12997-13006.

(69) Heine, C.; Girgsdies, F.; Trunschke, A.; Schlögl, R.; Eichelbaum, $\mathrm{M}$. The Model Oxidation Catalyst $\alpha-\mathrm{V}_{2} \mathrm{O}_{5}$ : Insights from Contactless in Situ Microwave Permittivity and Conductivity Measurements. Appl. Phys. A: Mater. Sci. Process. 2013, 112, 289-296.

(70) Abdullah, M. H.; Yusoff, A. N. Frequency Dependence of the Complex Impedances and Dielectric Behaviour of Some $\mathrm{Mg}-\mathrm{Zn}$ Ferrites. J. Mater. Sci. 1997, 32, 5817-5823.

(71) Shulman, H. S.; Damjanovic, D.; Setter, N. Niobium Doping and Dielectric Anomalies in Bismuth Titanate. J. Am. Ceram. Soc. 2000, 83, $528-532$.

(72) Zhuo, R. F.; Feng, H. T.; Chen, J. T.; Yan, D.; Feng, J. J.; Li, H. J.; Geng, B. S.; Cheng, S.; Xu, X. Y.; Yan, P. X. Multistep Synthesis, Growth Mechanism, Optical, and Microwave Absorption Properties of $\mathrm{ZnO}$ Dendritic Nanostructures. J. Phys. Chem. C 2008, 112, 11767-11775.

(73) Yusoff, A. N.; Abdullah, M. H.; Ahmad, S. H.; Jusoh, S. F.; Mansor, A. A.; Hamid, S. A. A. Electromagnetic and Absorption Properties of Some Microwave Absorbers. J. Appl. Phys. 2002, 92, 876882.

(74) Böttcher, C. J. F.; Bordewijk, P. Theory of Electric Polarization. Dielectrics in Time-Dependent Fields; 2 ed.; Elsevier Science: Amsterdam, The Netherlands, 1978; Vol. 2.
(75) Caldararu, M.; Scurtu, M.; Hornoiu, C.; Munteanu, C.; Blasco, T.; López Nieto, J. M. Electrical Conductivity of a MoVTeNbO Catalyst in Propene Oxidation Measured in Operando Conditions. Catal. Today 2010, 155, 311-318.

(76) Safonova, O. V.; Deniau, B.; Millet, J.-M. M. Mechanism of the Oxidation-Reduction of the MoVSbNbO Catalyst: In Operando X-ray Absorption Spectroscopy and Electrical Conductivity Measurements. J. Phys. Chem. B 2006, 110, 23962-23967.

(77) Millet, J. M. M.; Roussel, H.; Pigamo, A.; Dubois, J. L.; Jumas, J. C. Characterization of Tellurium in MoVTeNbO Catalysts for Propane Oxidation or Ammoxidation. Appl. Catal., A 2002, 232, 77-92.

(78) Lunkenbein, T.; Girgsdies, F.; Wernbacher, A.; Noack, J.; Auffermann, G.; Yasuhara, A.; Klein-Hoffmann, A.; Ueda, W.; Eichelbaum, M.; Trunschke, A.; et al. Direct Imaging of Octahedral Distortion in a Complex Molybdenum Vanadium Mixed Oxide. Angew. Chem., Int. Ed. 2015, 54, 6828-6831.

(79) Kawazoe, H.; Yasukawa, M.; Hyodo, H.; Kurita, M.; Yanagi, H.; Hosono, H. P-Type Electrical Conduction in Transparent Thin Films of $\mathrm{CuAlO}_{2}$. Nature 1997, 389, 939-942.

(80) Kawazoe, H.; Yanagi, H.; Ueda, K.; Hosono, H. Transparent pType Conducting Oxides: Design and Fabrication of p-n Heterojunctions. MRS Bull. 2000, 25, 28-36.

(81) Raebiger, H.; Lany, S.; Zunger, A. Origins of the p-Type Nature and Cation Deficiency in $\mathrm{Cu}_{2} \mathrm{O}$ and Related Materials. Phys. Rev. B 2007, 76, No. 045209.

(82) Robertson, J.; Clark, S. J. Limits to Doping in Oxides. Phys. Rev. B 2011, 83, No. 075205.

(83) Zhang, K. H. L.; Xi, K.; Blamire, M. G.; Egdell, R. G. P-Type Transparent Conducting Oxides. J. Phys.: Condens. Matter 2016, 28, No. 383002.

(84) Lany, S.; Osorio-Guillén, J.; Zunger, A. Origins of the Doping Asymmetry in Oxides: Hole Doping in $\mathrm{NiO}$ versus Electron Doping in ZnO. Phys. Rev. B 2007, 75, No. 241203.

(85) Herrmann, J.-M.; Vernoux, P.; Béré, K. E.; Abon, M. In Situ Study of Redox and of p-Type Semiconducting Properties of Vanadyl Pyrophosphate and of $\mathrm{V}-\mathrm{P}-\mathrm{O}$ Catalysts during the Partial Oxidation of $n$-Butane to Maleic Anhydride. J. Catal. 1997, 167, 106-117.

(86) Haber, J.; Witko, M.; Tokarz, R. Vanadium Pentoxide I. Structures and Properties. Appl. Catal., A 1997, 157, 3-22.

(87) Rouvet, F.; Herrmann, J.-M.; Volta, J.-C. Electrical Properties of Pure Vanadium Phosphate Phases and of VPO Catalysts Used in the Partial Oxidation of $n$-Butane to Maleic Anhydride. J. Chem. Soc., Faraday Trans. 1994, 90, 1441-1448.

(88) Deb, S. K.; Chopoorian, J. A. Optical Properties and ColorCenter Formation in Thin Films of Molybdenum Trioxide. J. Appl. Phys. 1966, 37, 4818-4825.

(89) Guo, Y.; Robertson, J. Origin of the High Work Function and High Conductivity of $\mathrm{MoO}_{3}$. Appl. Phys. Lett. 2014, 105, No. 222110.

(90) Hanson, E. D.; Lajaunie, L.; Hao, S.; Myers, B. D.; Shi, F.; Murthy, A. A.; Wolverton, C.; Arenal, R.; Dravid, V. P. Systematic Study of Oxygen Vacancy Tunable Transport Properties of Few-Layer $\mathrm{MoO}_{3-\mathrm{x}}$ Enabled by Vapor-Based Synthesis. Adv. Funct. Mater. 2017, 27, No. 1605380.

(91) Peelaers, H.; Chabinyc, M. L.; Van de Walle, C. G. Controlling nType Doping in $\mathrm{MoO}_{3}$. Chem. Mater. 2017, 29, 2563-2567.

(92) Allersma, T.; Hakim, R.; Kennedy, T. N.; Mackenzie, J. D. Structure and Physical Properties of Solid and Liquid Vanadium Pentoxide. J. Chem. Phys. 1967, 46, 154-160.

(93) Haemers, J.; Baetens, E.; Vennik, J. On the Electrical Conductivity of $\mathrm{V}_{2} \mathrm{O}_{5}$ Single Crystals. Phys. Status Solidi A 1973, 20 , 381-386.

(94) Ioffe, V. A.; Patrina, I. B. Comparison of the Small-Polaron Theory with the Experimental Data of Current Transport in $\mathrm{V}_{2} \mathrm{O}_{5}$. Phys. Status Solidi B 1970, 40, 389-395.

(95) Sanchez, C.; Henry, M.; Grenet, J. C.; Livage, J. Free and Bound Polarons in Vanadium Pentoxide. J. Phys. C: Solid State Phys. 1982, 15, $7133-7141$

(96) Tahini, H. A.; Tan, X.; Lou, S. N.; Scott, J.; Amal, R.; Ng, Y. H.; Smith, S. C. Mobile Polaronic States in $\alpha-\mathrm{MoO}_{3}: \mathrm{An}$ ab Initio 
Investigation of the Role of Oxygen Vacancies and Alkali Ions. ACS Appl. Mater. Interfaces 2016, 8, 10911-10917.

(97) Ren, G.-K.; Wang, S.-Y.; Zhu, Y.-C.; Ventura, K. J.; Tan, X.; Xu, W.; Lin, Y.-H.; Yang, J.; Nan, C.-W. Enhancing Thermoelectric Performance in Hierarchically Structured $\mathrm{BiCuSeO}$ by Increasing Bond Covalency and Weakening Carrier-Phonon Coupling. Energy Environ. Sci. 2017, 10, 1590-1599.

(98) Cheng, M.-J.; Goddard, W. A. In Silico Design of Highly Selective Mo-V-Te-Nb-O Mixed Metal Oxide Catalysts for Ammoxidation and Oxidative Dehydrogenation of Propane and Ethane. J. Am. Chem. Soc. 2015, 137, 13224-13227.

(99) Grasselli, R. K. Selectivity Issues in (Amm)oxidation Catalysis.

Catal. Today 2005, 99, 23-31.

(100) Knockaert, G. Tellurium and Tellurium Compounds. In Ullmann's Encyclopedia of Industrial Chemistry; Wiley-VCH Verlag GmbH \& Co. KGaA: Weinheim, 2012; pp 685-695.

(101) Ahluwalia, G. K. Applications of Chalcogenides: $S$, Se, and Te, 1st ed.; Springer International Publishing: Cham, Switzerland, 2017.

(102) Siritanon, T.; Laurita, G.; Macaluso, R. T.; Millican, J. N.; Sleight, A. W.; Subramanian, M. A. First Observation of Electronic Conductivity in Mixed-Valence Tellurium Oxides. Chem. Mater. 2009, 21, 5572-5574.

(103) Chen, Z.; Huang, L.; Zhang, Q.; Xi, Y.; Li, R.; Li, W.; Xu, G.; Cheng, H. Electronic Structures and Transport Properties of n-TypeDoped Indium Oxides. J. Phys. Chem. C 2015, 119, 4789-4795.

(104) Jiang, X.-h.; Shi, J.-j.; Zhang, M.; Zhong, H.-x.; Huang, P.; Ding, Y.-m.; Cao, X.; Wu, M. Modulation of Electronic and Optical Properties of $\mathrm{ZnO}$ by Inserting an Ultrathin $\mathrm{ZnX}(\mathrm{X}=\mathrm{S}$, Se and $\mathrm{Te})$ Layer to Form Short-Period $(\mathrm{ZnO})_{5} /(\mathrm{ZnX})_{1}$ Superlattice. J. Alloys Compd. 2017, 711, 581-591.

(105) Liu, Q.-J.; Jiao, Z.; Liu, F.-S.; Liu, Z.-T. Influences of S, Se, Te and Po Substitutions on Structural, Electronic and Optical Properties of Hexagonal $\mathrm{CuAlO}_{2}$ Using GGA and B3LYP Functionals. Phys. Chem. Chem. Phys. 2016, 18, 14317-14322.

(106) Liu, Q.-J.; Zhang, N.-C.; Liu, F.-S.; Liu, Z.-T. Effects of Chalcogen Substitution on Electronic Properties and Chemical Bondings of Delafossite $\mathrm{CuAlO}_{2}$. Phys. Status Solidi B 2014, 251, $1630-1634$

(107) Zhu, Y.; Sushko, P. V.; Melzer, D.; Jensen, E.; Kovarik, L.; Ophus, C.; Sanchez-Sanchez, M.; Lercher, J. A.; Browning, N. D. Formation of Oxygen Radical Sites on MoVNbTeOx by Cooperative Electron Redistribution. J. Am. Chem. Soc. 2017, 139, 12342-12345.

(108) Morrison, S. R. The Chemical Physics of Surfaces; Plenum Press: New York, 1977.

(109) Jaegermann, W. Surface Studies of Layered Materials in Relation to Energy Converting Interfaces. In Photoelectrochemistry and Photovoltaics of Layered Semiconductors; Aruchamy, A., Ed. Kluwer Academic Publishers: Dordrecht, The Netherlands, 1992; pp 195-295.

(110) McCafferty, E.; Zettlemoyer, A. C. Adsorption of Water Vapour on $\alpha-\mathrm{Fe}_{2} \mathrm{O}_{3}$. Discuss. Faraday Soc. 1971, 52, 239-254.

(111) Farahani, H.; Wagiran, R.; Hamidon, M. Humidity Sensors Principle, Mechanism, and Fabrication Technologies: A Comprehensive Review. Sensors 2014, 14, 7881-7939.

(112) Li, Z.; Haidry, A. A.; Gao, B.; Wang, T.; Yao, Z. The Effect of Co-Doping on the Humidity Sensing Properties of Ordered Mesoporous $\mathrm{TiO}_{2}$. Appl. Surf. Sci. 2017, 412, 638-647.

(113) Qu, W.; Meyer, J.-U. A Novel Thick-Film Ceramic Humidity Sensor. Sens. Actuators, B 1997, 40, 175-182.

(114) Wang, C.; Yin, L.; Zhang, L.; Xiang, D.; Gao, R. Metal Oxide Gas Sensors: Sensitivity and Influencing Factors. Sensors 2010, 10, 2088-2106.

(115) Zang, W.; Li, P.; Fu, Y.; Xing, L.; Xue, X. Hydrothermal Synthesis of Co-ZnO Nanowire Array and Its Application as PiezoDriven Self-Powered Humidity Sensor with High Sensitivity and Repeatability. RSC Adv. 2015, 5, 84343-84349.

(116) Grasselli, R. K. Fundamental Principles of Selective Heterogeneous Oxidation Catalysis. Top. Catal. 2002, 21, 79-88. 